3.

Derecho constitucional 

Revista de Derecho

de la Pontificia Universidad Católica de Valparaíso

XXXVI (Valparaíso, Chile, 2011, $1^{\text {er }}$ Semestre)

[pp. 167 - 206]

\title{
LA APLICACIÓN DEL PRINCIPIO DE PROPORCIONALIDAD EN ORDEN A JUZGAR SOBRE LA LICITUD O ILICITUD DE UNA RESTRICCIÓN A DERECHOS FUNDAMENTALES
}

["The Application of the Proportionality Principle so as to Judge on the Legality or Illegality of a Restriction to Fundamental Rights"]

\author{
L. Iván Díaz García* \\ Universidad Católica de Temuco, Chile
}

\begin{abstract}
RESUMEN
Las reglas y tareas que en forma de gradas estructuran el examen de proporcionalidad de medidas restrictivas de derechos fundamentales permiten generar decisiones judiciales correctas porque maximizan el disfrute de aquellos derechos, dentro de las posibilidades conferidas por las justificaciones en que se fundan tales medidas. Este análisis permite advertir, además, que el examen de proporcionalidad es un procedimiento de decisión claro, relativamente sencillo e intersubjetivamente controlable.

Palabras Clave

Restricción de derechos fundamentales - Principio de proporcionalidad - Regla de la idoneidad - Regla de la necesidad - Regla de la ponderación.
\end{abstract}

\begin{abstract}
The norms and duties that, as steps in a stair, structure the examination of proportionality of fundamental rights restrictive measures, allow making correct legal decisions since they maximize the enjoyment of such rights within the possibilities granted by the justifications underlying such measures. Likewise, this analysis allows us to be aware that the proportionality test is a relatively simple, clear decision-making procedure, controllable from an intersubjectively stand point.

KEYWORDS

Restriction of fundamental rights Principle of proportionality - Rule of adequacy - Rule of necessity - Rule of balance.
\end{abstract}

[Recibido el 28 de octubre de 2010 y aprobado el 10 de junio de 2011].

* Doctor en Derecho por la Universidad Carlos III, Madrid. Académico en la Facultad de Ciencias Jurídicas de la Universidad Católica de Temuco. Dirección postal: Manuel Montt N ${ }^{\circ}$ 56, Temuco. Casilla 15-D, Temuco Chile. Correo electrónico: ivandiaz@uctemuco.cl 


\section{INTRODUCCIÓN}

\section{Planteamiento del problema.}

Con fecha 28 de febrero de 2008 se publicó en el Diario Oficial la resolución exenta $\mathrm{N}^{\circ} 95$, de la Secretaría Regional Ministerial de Transportes y Telecomunicaciones de la Región de la Araucanía. En virtud de esta resolución se prohibió, a partir del 3 de marzo del mismo año, la circulación de taxis colectivos de lunes a viernes, entre 7:00 y 22:00 horas, dentro de la comuna de Temuco, de acuerdo al último dígito de su placa patente y a razón de dos dígitos por día, siempre que estuvieren prestando servicios de taxi colectivo. El 18 de abril del mismo año, y acogiendo una acción de protección, la Corte de Apelaciones dejó sin efecto esta resolución por estimar que lesionaba los derechos fundamentales de los afectados ${ }^{1}$. La Corte Suprema revocó esta decisión porque, a su juicio, la resolución no afectaba ningún derecho fundamental y constituía el ejercicio de una atribución legalmente conferida a la autoridad administrativa ${ }^{2}$.

El 18 de mayo de 2005 una empresa de Puerto Montt utilizó las cámaras de seguridad instaladas en la sala de procesos, es decir, en el lugar en el que los trabajadores prestan sus servicios, para realizar seguimientos y encuadres a determinados trabajadores que tenían la calidad de dirigentes sindicales. El 30 de septiembre del mismo año la Corte de Apelaciones de dicha ciudad rechazó la acción de protección deducida por los respectivos sindicatos, por considerar que no se reunían los presupuestos de un acto ilegal o arbitrario que lesionara algún derecho fundamental ${ }^{3}$. Mediante sentencia del 5 de enero de 2006, la Corte Suprema revocó esa decisión y sentenció que la empresa debía ajustar a la legalidad la utilización de video cámaras de vigilancia, de modo de no afectar el derecho fundamental a la intimidad de los trabajadores que en ella laboran ${ }^{4}$.

A inicios del año 2009 el Hospital Base de Valdivia remitió un oficio al juzgado de familia de la misma ciudad, solicitando una medida de protección para un niño de 11 años de edad que padece de leucemia linfoblástica aguda. En el caso, la oncóloga infantil tratante recomendaba aplicar un nuevo tratamiento contra la enfermedad, que ahora incluía cáncer testicular,

\footnotetext{
${ }^{1}$ Sentencia de la Corte de Apelaciones de Temuco de 25 de abril de 2008, recaída en la causa rol $\mathrm{N}^{\circ} \mathrm{N}^{\circ} 300-2008$, sobre recurso de protección.

${ }^{2}$ Sentencia de la Corte Suprema de 21 de septiembre de 2008, recaída en la causa rol N ${ }^{\circ}$ 2546-2008, sobre recurso de protección.

${ }^{3}$ Sentencia de la Corte de Apelaciones de Puerto Montt de 30 de septiembre de 2005, recaída en la causa rol $N^{\circ} 156-2005$, sobre recurso de protección.

${ }^{4}$ Sentencia de la Corte Suprema de 5 de enero de 2006, recaída en la causa rol N ${ }^{\circ}$ 5234-05, sobre recurso de protección.
} 
asegurando un $40 \%$ de posibilidad de sobrevida. La madre se negaba a esta intervención debido a los padecimientos que había provocado a su hijo un tratamiento anterior, el que adicionalmente había resultado infructuoso. Mediante resolución de 7 de abril de 2009 el juzgado de familia resolvió que se debía practicar al niño el tratamiento que la ciencia médica aconseje para salvaguardar su derecho a la vida ${ }^{5}$. La Corte de Apelaciones de Valdivia revocó la sentencia dictada por el juzgado de familia, y determinó que a la madre correspondía tomar una decisión en este caso, previa audiencia del menor ante el mismo juzgado.

Los tres casos concisamente expuestos, y muchos otros de la realidad cotidiana, permiten constatar al menos dos cosas bastante evidentes. Primero, que tanto entidades públicas como privadas adoptan medidas que restringen el disfrute de los derechos fundamentales, normalmente con una real o aparente buena justificación. Segundo, que al evaluar la constitucionalidad de esa clase de medidas los órganos que ejercen jurisdicción pueden generar decisiones contradictorias, debido a las dudas que provoca preferir los derechos fundamentales o aquella real o aparente buena justificación. El cruce de estas dos constataciones evidencia una serie de problemas que no pueden dejar indiferente al ciudadano común, al abogado litigante, a los propios jueces y menos al jurista. ¿Cuál de esas decisiones judiciales es la correcta? O incluso antes: ¿es correcta alguna de esas decisiones judiciales? Y, en cualquier caso: ¿cómo obtener decisiones judiciales correctas cuando se trata de evaluar la constitucionalidad de las medidas restrictivas de derechos fundamentales?

Para enfrentar este problema procedimental resulta imprescindible resolver, previamente, un problema conceptual: qué se entiende por decisión judicial correcta cuando se trata de evaluar una medida restrictiva de derechos fundamentales. Como este asunto no constituye el tema central de la presente investigación, sino sólo un supuesto necesario para el desarrollo de la misma, a continuación se ofrecerá una muy concisa respuesta para el mismo.

Al respecto no parece necesario justificar en demasía que uno de los principios fundantes del ordenamiento constitucional chileno es el respeto, protección y promoción de los derechos fundamentales ${ }^{7}$. Al mismo tiempo,

${ }^{5}$ Sentencia del Juzgado de familia de Valdivia de 7 de abril de 2009, recaída en la causa rol $\mathrm{N}^{\circ} 178$, sobre medida de protección.

${ }^{6}$ Sentencia de la Corte de Apelaciones de Valdivia de 14 de mayo de 2009, recaída en la causa rol $N^{\circ} 103-2009$, sobre medida de protección.

${ }^{7}$ Para justificar este aserto basta con recordar lo sostenido por el Tribunal Constitucional chileno en sus recientes sentencias recaídas en las causas rol $\mathrm{N}^{\circ} 1710$, de 6 de agosto de 2010, $\mathrm{y} \mathrm{N}^{\circ} 1243$, de 30 de diciembre de 2008. En el considerando octogésimo séptimo de la primera, y transcribiendo lo expresado en el considerando décimo octavo 
resulta evidente que con frecuencia la autoridad debe establecer restricciones al ejercicio de tales derechos con la finalidad de satisfacer otros intereses 8 . El cruce de estas dos variables permite afirmar que una decisión judicial que evalúa la constitucionalidad de una medida restrictiva de derechos fundamentales es correcta si permite el disfrute de los derechos fundamentales en el mayor grado posible, dentro de las posibilidades que confieren las justificaciones en que se funda la medida que pretende su restricción.

Así entendido lo que es una decisión judicial correcta, resulta pertinente enfrentar el problema relativo a cómo obtener decisiones judiciales correctas. Para obtener decisiones judiciales correctas cuando se trata de evaluar medidas restrictivas de derechos fundamentales que presentan una real o aparente buena justificación es necesario contar con instrumentos adecuados. Es instrumento adecuado el que permite resolver el caso atendiendo a los dos intereses en colisión, esto es, la necesidad de asegurar el disfrute de los derechos fundamentales en el mayor grado posible, y la necesidad de considerar las razones que se han esgrimido para justificar su restricción.

Uno de tales instrumentos es el habitualmente denominado principio de proporcionalidad, el que aquí será llamado examen de proporcionalidad'. Se trata de un mecanismo al servicio del juzgador que persigue proveer soluciones para resolver adecuadamente los conflictos entre los derechos fundamentales y otros derechos fundamentales o bienes constitucionales, a través de un razonamiento que contrasta intereses jurídicos opuestos para

de la sentencia recaída en la causa rol $\mathrm{N}^{\circ} 1287$, sostuvo que es menester poner de relieve que, "en armonía con lo preceptuado en el Artículo 5o, inciso segundo, los órganos públicos y los agentes privados, cada cual en ejercicio de la competencia y facultades que les han conferido, respectivamente, la Constitución y la ley, no sólo están obligados a respetar esos derechos, sino que, además, a protegerlos y promoverlos". Por su parte, en el considerando vigésimo segundo de la segunda de las sentencias mencionadas expresó que "los derechos fundamentales constituyen para el derecho contemporáneo el máximo objeto de protección y la finalidad última del sistema jurídico".

${ }^{8}$ AleXy, R., Teoría de los derechos fundamentales (Traducción castellana de Ernesto Garzón Valdés, Madrid, Centro de Estudios Políticos y Constitucionales, 2001), p. 267, expresa esta idea del siguiente modo: "El concepto de restricción de un derecho nos parece familiar y no problemático. Que los derechos están sujetos a restricciones y pueden ser delimitados o limitados parece ser un conocimiento evidente y hasta trivial".

${ }^{9}$ Esta opción se funda en que el habitualmente denominado principio de proporcionalidad no presenta la estructura de los principios. Al respecto véase ALEXY, R., Teoría, cit. (n. 8), especialmente pp. 86 y 87 . En realidad constituye un procedimiento a través del cual se examina la constitucionalidad de medidas restrictivas de derechos fundamentales y de ahí que, siguiendo a ClérICO, Laura, El examen de proporcionalidad en el Derecho constitucional (Buenos Aires, Eudeba, 2009), se le ha denominado examen de proporcionalidad. 
poder determinar si una medida restrictiva está justificada o es adecuada - no excesiva- respecto al fin que se persigue ${ }^{10}$. Por añadidura, se trata de una "metaherramienta", pues permite evaluar la evaluación realizada por el juez a la hora de ponderar distintos intereses constitucionales que entran en conflicto ${ }^{11}$.

Ahora bien, el examen de proporcionalidad puede ser analizado desde diversas perspectivas, tales como la conceptual, la empírica o la normativa. Es conceptual si se trata de precisar en qué consiste. Es empírica si se estudia cómo opera o se aplica. Y es normativa si se prescribe cómo debe operar o cómo se debe aplicar la proporcionalidad ${ }^{12}$.

Pues bien, esta investigación se inscribe en la perspectiva normativa, pues expone cómo se debe aplicar el examen de proporcionalidad. En este sentido, el problema de que se tratará puede ser expresado mediante la siguiente pregunta: ¿cómo se debe aplicar el examen de proporcionalidad? Al responder esta pregunta será posible mostrar que el examen de proporcionalidad efectivamente conduce a decisiones judiciales correctas, es decir, decisiones que permiten el mayor disfrute posible de los derechos fundamentales, dentro de las posibilidades que confieren las justificaciones en que se funda la medida que pretende su restricción. Adicionalmente será posible mostrar que el examen de proporcionalidad provee un procedimiento claro y sencillo para alcanzar esas decisiones judiciales correctas.

\section{Importancia del problema planteado.}

Como se puede suponer, el problema de cómo aplicar el examen de proporcionalidad cuando se trata de evaluar la constitucionalidad de una medida restrictiva de derechos fundamentales no es baladí por varias razones.

a) La primera de ellas es la más evidente. Comprender el modo en que se aplica el examen de proporcionalidad es importante porque la decisión que se adopte en la materia incidirá inmediatamente en el disfrute de los derechos fundamentales. De este modo, una decisión judicial correcta autorizará o rechazará la restricción de derechos fundamentales sólo cuando ello sea jurídi-

${ }^{10}$ CARPIZO, Jorge, El Tribunal Constitucional y el control de la reforma constitucional, en Boletin Mexicano de Derecho Comparado, 125 (mayo-agosto, 2009), p. 757.

${ }^{11}$ VIdal Fueyo, Camino, El principio de proporcionalidad como parámetro de constitucionalidad de la actividad del juez, en Anuario de Derecho constitucional Latinoamericano, 2 (2009) 2, p. 445, formula esta idea respecto del juez penal, pero nada obsta a aplicarla a todo órgano que ejerce jurisdicción.

${ }^{12}$ En similar sentido, véase: Martínez Zorrilla, David, Dilemas morales y Derecho, en Discusiones, 8 (2008), p. 20. Corresponde advertir que en este trabajo se ha preferido la expresión "empírica" por sobre el término "metodológica", empleado por este autor por resultar más precisa. 
camente procedente. Una decisión judicial incorrecta, en cambio, restringirá indebidamente los derechos fundamentales, privando a su titular de su disfrute efectivo o de algún grado de ejercicio del mismo. Esto es especialmente sensible si se considera que los tribunales deben evaluar cotidianamente la constitucionalidad de medidas restrictivas de derechos fundamentales, como lo muestran los casos expuestos al inicio de este trabajo.

b) Una segunda razón es que, pese a la centralidad de lo recién indicado, la jurisprudencia del Poder Judicial chileno no cuenta con criterios jurídicos que le permitan generar una sólida doctrina constitucional. Más bien al contrario, las decisiones vinculadas con el disfrute y restricción de los derechos fundamentales parecen entregadas a una impredecible discrecionalidad ${ }^{13}$. En este sentido, la situación contradice frontalmente la aspiración de certeza y previsibilidad que caracteriza al Derecho ${ }^{14}$, y que sólo se puede alcanzar si se aplican criterios adecuados para arribar a decisiones correctas.

El problema de que trata este trabajo es relevante, en tercer lugar, porque la noción de proporcionalidad ha sido intuitivamente utilizada, aunque en forma infrecuente e imprecisa, por el Poder Judicial chileno ${ }^{15}$. Esa intuición

${ }^{13}$ Ferrada Bórquez, Juan Carlos, Los derechos fundamentales y el control constitucional, en Revista de Derecho, 17 (Valdivia, 2004) [citado en línea el 14 de octubre de 2010, sin paginación], afirma de manera categórica que todos los conflictos jurídicos entre derechos fundamentales descansan "en resoluciones dictadas caso a caso, que se muestran inconsistentes y de contenido variable según las partes y elementos metajurídicos en conflicto".

${ }^{14}$ Barranco Avilés, María del Carmen, Derechos y decisiones interpretativas (Madrid - Barcelona, Marcial Pons, 2004), pp. 19-20.

${ }^{15}$ Así, por ejemplo, la Corte de Apelaciones de Santiago en sentencia de 12 de diciembre de 2006, recaída en la causa rol $\mathrm{N}^{\circ} 5717$, sobre recurso de protección, acogió la acción deducida por un grupo de escolares en contra de las sanciones aplicadas por su establecimiento educacional fundándose en que tales sanciones "deben ser estimadas como arbitrarias, ya que en su imposición no ha existido ni racionalidad ni proporcionalidad" (considerando $4^{\circ}$ ). El Tribunal Oral en lo Penal de Concepción, por su parte, solicitó, mediante oficio de 30 de julio de 2007, un pronunciamiento al Tribunal Constitucional respecto de la constitucionalidad del artículo $450 \mathrm{CP}$., fundándose en que por la vía de castigar " a una persona acusada de un delito en una etapa imperfecta de desarrollo, como si fuera consumado, podría comprometerse la proporcionalidad de la pena a imponer" (véase sentencia recaída en la causa rol № 829 , de 6 de marzo de 2008, del Tribunal Constitucional). En fin, una excepcionalmente completa aplicación del principio de proporcionalidad puede encontrarse en la sentencia del juzgado del trabajo de Copiapó de 15 de septiembre de 2008, recaída en la causa rol $N^{\circ} 1-2008$, aunque la procedencia de aplicar este principio es objetada por FERRADA BórQUEZ, Juan Carlos, en Abriendo camino en la tutela de derechos fundamentales en materia laboral: buenas intenciones, malos instrumentos (Juzgado de Letras del Trabajo de Copiapó), en Revista de Derecho, 21 (Valdivia, 2008) 2 [citado en línea el 2 de septiembre de 2010], pp. 251-271. 
debe ser orientada mediante la explicitación del modo en que se debe aplicar dicho juicio, porque son los tribunales de justicia los llamados a evaluar la constitucionalidad de las medidas restrictivas de derechos fundamentales ${ }^{16}$. Esto permitirá pasar de un uso intuitivo, infrecuente e impreciso a una aplicación más exacta, oportuna y precisa del examen de proporcionalidad.

c) En fin, el análisis del modo en que debe aplicarse el examen de proporcionalidad es relevante porque se trata de un criterio de evaluación de constitucionalidad consolidado por los Tribunales Constitucionales de Alemania ${ }^{17}$, España ${ }^{18}$, y Colombia ${ }^{19}$, y por el Tribunal Supremo de Méxi$\mathrm{CO}^{20}$, entre otros. Además, ha sido cada vez más utilizado por el Tribunal Constitucional chileno ${ }^{21}$, e incluso invocado por la Dirección del Trabajo

${ }^{16}$ Rojas, Ivonne Yenissey, El principio de proporcionalidad de las penas (s.l., s.d.), p. 2, afirma que "sólo los órganos judiciales (requisito subjetivo de judicialidad) son los constitucionalmente llamados a garantizar de forma inmediata la eficacia de los derechos, y a su juicio queda la decisión en torno a la proporcionalidad de las medidas limitativas de los mismos".

${ }^{17} \mathrm{Al}$ efecto véase, por ejemplo, CLÉRICO, L., cit. (n. 9).

${ }^{18}$ Singularmente expresivo a este respecto es Sarmiento, Daniel, El principio de proporcionalidad y la defensa de la autonomía local, en Revista de Administración Pública, 162 (septiembre-diciembre de, 2003), p. 145, cuando expresa: "Desde hace aproximadamente quince años, el Derecho público español vive cada vez más pendiente de la evolución del principio de proporcionalidad. A pesar de la antigüedad de esta máxima y sus implicaciones filosóficas, que evidentemente van más allá de lo estrictamente jurídico, nuestro ordenamiento ha presenciado una preeminencia de la proporcionalidad hasta unos extremos sin duda desconocidos en nuestra historia legal. No sólo el Tribunal Constitucional ha incorporado a su arsenal jurisprudencial las virtualidades del principio, sino también la jurisdicción contencioso-administrativa, hasta hacer del mismo una norma que lo controla todo".

${ }^{19} \mathrm{Al}$ respecto puede verse Bernal Pulido, Carlos, El juicio de igualdad en la jurisprudencia de la Corte Constitucional Colombiana, en VegA Gómez, Juan - Corzo SosA, Edgar. Instrumentos de tutela y justicia constitucional, Memoria del VII Congreso Iberoamericano de Derecho constitucional (Ciudad de México, Instituto de Investigaciones Jurídicas, 2002), pp. 51-74.

${ }^{20}$ Véase SÁNCHEz GIL, Rubén, El principio de proporcionalidad en la jurisprudencia mexicana, en AlEXY, R. y otros, El principio de proporcionalidad en la interpretación jurídica (Santiago de Chile, Librotecnia, 2010), especialmente pp. 333 a 342.

${ }^{21}$ No resulta posible obviar que el Tribunal Constitucional chileno parece haber iniciado la aplicación del principio de proporcionalidad en forma sostenida. Así se puede advertir, por ejemplo, en las sentencias recaídas en las causas rol $N^{\circ} 1710$, de 6 de agosto de 2010 , considerando $100^{\circ}$, rol $\mathrm{N}^{\circ} 1452$, de 5 de agosto de 2010 , considerando $28^{\circ}$, y rol $\mathrm{N}^{\circ} 1243$, de 30 de diciembre de 2008 , considerando $23^{\circ}$, en todas las cuales se señalan expresamente a todas o a algunas de las tres reglas constitutivas de la proporcionalidad, esto es, la adecuación, la idoneidad y la ponderación. Sin embargo, Zúñiga Añasco estima que "este órgano no ha sido capaz de construir una dogmática en materia de proporcionalidad que satisfaga los requisitos de estabilidad, coherencia 
de Chile 22 .

Todo lo dicho permite comprender, aunque sin pretensiones de exhaustividad, por qué resulta importante explicar el modo en el que se debe aplicar el examen de proporcionalidad para evaluar la constitucionalidad de una medida restrictiva de derechos fundamentales.

\section{Plan de trabajo.}

Según se indicó más arriba, el presente trabajo tiene por finalidad exponer el modo en el que se debe aplicar el examen de proporcionalidad para evaluar la constitucionalidad de medidas restrictivas de derechos fundamentales que presentan una real o aparente buena justificación. Esto permitirá, al mismo tiempo, mostrar que dicho examen constituye, al mismo tiempo, una eficaz, clara y sencilla herramienta para alcanzar decisiones judiciales correctas.

Con miras al adecuado cumplimiento de este objetivo la presente investigación se vertebra en torno a tres apartados, cada uno relativo a la aplicación de una de las reglas que estructuran el examen de proporcionalidad ${ }^{23}$. En consecuencia, en tales apartados se trata, sucesivamente, de la regla de idoneidad (II), de la regla de necesidad (III) y de la regla de proporcionalidad en sentido estricto, la que en este trabajo será denominada de ponderación (IV). Las respectivas explicaciones van precedidas de una concisa referencia a la estructura de cada una de las reglas mencionadas, con miras a una mejor comprensión del modo en que deben aplicarse. El trabajo finaliza con las pertinentes conclusiones $(\mathrm{V})$.

\section{LA REGLA DE IDONEIDAD}

\section{Significado de la regla de idoneidad.}

La regla de idoneidad evalúa la constitucionalidad de una medida que afecta el disfrute de derechos fundamentales en dos sentidos. Por una parte,

y refinamiento conceptual exigibles a un intérprete privilegiado de la Constitución”. $\mathrm{Al}$ respecto véase ZúNIGa AÑasco, Yanira, El principio de proporcionalidad como herramienta de racionalidad. Un análisis critico de su aplicación en la jurisprudencia del Tribunal Constitucional chileno, en Ius et Praxis, 16 (Talca, 2010) 2, p. 270.

${ }^{22}$ Véase Ordinario $\mathrm{N}^{\circ} 2210 / 035$, de la Dirección del Trabajo, de 10 de junio de 2009 , en el que se invoca reiteradamente el principio de proporcionalidad. Pese a la claridad conceptual que exhibe el documento en referencia, parece existir cierta confusión al momento de utilizar la expresión proporcionalidad en el mismo.

${ }^{23}$ En esta investigación se denominará reglas a los tres elementos de juicio que conforman el principio de proporcionalidad y que habitualmente se conocen como principios o reglas. Ello se debe a que, siguiendo a Alexy, no presentan la estructura de los principios, sino de las reglas. Al respecto véase Alexy, R., Teoría, cit. (n. 8), especialmente pp. 86-87. 
analiza si la medida o su finalidad son legítimas ${ }^{24}$, lo que aquí se denominará idoneidad teleológica. Por otra parte, analiza si la medida es adecuada para promover esa finalidad ${ }^{25}$, lo que aquí se llamará idoneidad técnica ${ }^{26}$. Sólo si la medida es admisible en estos dos sentidos se podrá afirmar que ha superado el estándar exigido por esta primera regla ${ }^{27}$.

${ }^{24}$ Bernal Pulido, C., El principio de proporcionalidad y los derechos fundamentales (2 ${ }^{\text {a }}$ edición, Madrid, Centro de Estudios Políticos y Constitucionales, 2005), p. 689, explica que la regla de idoneidad impone, como primera exigencia, que la medida de intervención en los derechos fundamentales "tenga un fin constitucionalmente legítimo". SÁnchez Gil, R., El principio de proporcionalidad (Ciudad de México, Instituto de Investigaciones Jurídicas, 2007), p. 40, se pronuncia en similar sentido al afirmar que la medida "debe tener un fin legítimo". SAPAG, Mariano, El principio de proporcionalidad y de razonabilidad como limite constitucional al poder del Estado: Un estudio comparado, en Dikaion, 22 (diciembre 2008) 17, p. 186, por su parte, sostiene que primero se debe "detectar la finalidad de la medida para luego determinar si es constitucional y socialmente relevante.

${ }^{25}$ Bernal Pulido, C., El principio, cit. (n. 24), p. 689, explica que la regla de idoneidad exige, en segundo lugar, que la medida evaluada sea idónea para favorecer la obtención de la finalidad perseguida. SánCHEZ GIL, R., El principio, cit. (n. 24), p. 40, plantea que la medida "debe ser objetivamente idónea o adecuada para realizarlo [el fin], es decir, que por su medio efectivamente pueda alcanzarse una situación que satisfaga el fin a que supuestamente sirve, por ser ella su consecuencia natural". SAPAG, M., cit. (n. 24), p. 186, se pronuncia en el mismo sentido de los anteriores al expresar que "una vez detectado el fin, se debe analizar si el medio es idóneo para alcanzarlo".

${ }^{26} \mathrm{La}$ expresión idoneidad técnica sigue de cerca la fórmula "adecuación técnica" empleada por Clérico, L., cit. (n. 9).

${ }^{27}$ Conviene advertir que no existe consenso en cuanto a que la idoneidad teleológica integre la regla de idoneidad. Así, por ejemplo, González BeIlfuss, Markus, Últimas tendencias en la interpretación del principio de proporcionalidad por parte del Tribunal Constitucional español, en CARrasco Durán, Manuel - Pérez Royo, Francisco Javier - Urías Martínez, Joaquín - Terol Becerra, Manuel José (coordinadores), Derecho constitucional para el siglo XXI: actas del VIII Congreso Iberoamericano de Derecho Constitucional (España, Aranzadi, 2006), II, p. 14, sostiene que el Tribunal Constitucional español ha excluido de la regla de idoneidad lo que aquí se ha denominado idoneidad teleológica. Al respecto expone que, "además de estos tres elementos del principio de proporcionalidad, son varias las sentencias que también hacen referencia a lo que el Tribunal denomina su prius lógico: la finalidad de la medida objeto de control. Aunque esta finalidad también puede ser analizada en el seno del juicio de idoneidad, los especiales problemas que plantea han llevado al Tribunal a examinarla de modo autónomo y previo al análisis de la idoneidad, la necesidad y la proporcionalidad en sentido estricto". Perello Domenech, Isabel, El principio de proporcionalidad y la jurisprudencia constitucional, en Jueces para la democracia, 28 (1997), p. 70, incluye en la regla de idoneidad exclusivamente a lo que aquí se ha denominado idoneidad técnica. En fin, y sin ánimo de exhaustividad, SARMiento, cit. (n. 18), p. 160, nota al pie 34, por su parte, utiliza la expresión "coherencia" entre medios y fines para aludir a la regla de idoneidad, lo que en realidad sólo responde a la idoneidad técnica. 
Ahora bien, la medida evaluada es teleológicamente idónea si la propia medida o los fines perseguidos con la misma son legítimos. El problema implícito en esta definición consiste en dilucidar qué significa afirmar la legitimidad de una medida restrictiva de derechos fundamentales o de los fines de la misma. Pues bien, una medida o su finalidad son legítimas si no están constitucionalmente prohibidas $\mathrm{y}$, además, si la medida cuenta con justificación constitucional.

Una medida restrictiva de derechos fundamentales o su finalidad pueden estar prohibidas constitucionalmente de manera definitiva o prima facie. La prohibición es absoluta si no admite excepción alguna, porque el medio o la finalidad pugnan con normas constitucionales que así lo establecen, como sería el caso del favorecimiento de la esclavitud o la admisión de la tortura. La prohibición es prima facie si es de carácter general, de modo que admite excepciones, porque el medio o la finalidad pugnan con normas constitucionales que bajo ciertas condiciones pueden ser contravenidas ${ }^{28}$.

Una medida restrictiva de derechos fundamentales está constitucionalmente justificada si tiene respaldo en normas constitucionales. En efecto, el principio de supremacía constitucional exige que las restricciones a los derechos fundamentales sólo provengan de otras normas constitucionales, es decir, de normas que tengan su misma jerarquía ${ }^{29}$. Que las restricciones provengan de otras normas constitucionales significa que han sido estatuidas en normas constitucionales o que han sido estatuidas en normas infraconstitucionales autorizadas por normas constitucionales. Alexy denomina a las primeras restricciones directamente constitucionales y a las segundas, restricciones indirectamente constitucionales ${ }^{30}$. Las restricciones directamente

${ }^{28}$ Clérico, L., cit. (n. 9), especialmente pp. 85-86.

${ }^{29}$ SÁnchez GIL, R., El principio, cit. (n. 24), pp. 41 y 42. afirma que el fin de la medida "debe estar permitido por la ley suprema y tender a satisfacer un principio constitucional, lo que evidentemente excluye como legítimo a todo fin prohibido por ella, pues limitar la eficacia de los derechos fundamentales en nombre de cualquier "interés" afectaría el principio de supremacía constitucional”. En efecto, si el acto o norma pretende restringir un derecho fundamental basándose en intereses que carecen de asidero constitucional, puede ser considerado materialmente contrario a la Constitución [cfr. Silva Bascuñán, Alejandro, Tratado de Derecho constitucional (2a edición, Santiago de Chile, Jurídica de Chile, 1997), I, pp. 122-123].

${ }^{30}$ De ahí que Alexy, R., Teoría, cit. (n. 8), p. 277, exprese que "Los derechos fundamentales, en tanto derechos de rango constitucional, pueden ser restringidos sólo a través de, o sobre la base de, normas con rango constitucional”. Sobre estas categorías, Alexy precisa que "las restricciones de derechos fundamentales son siempre o bien normas de rango constitucional o normas de rango inferior al de la Constitución, a las que autorizan dictar normas constitucionales. Las restricciones de rango constitucional son directamente constitucionales; las restricciones de rango inferior a la Constitución, indirectamente constitucionales" (las cursivas son del original). 
constitucionales son los derechos fundamentales y los bienes constituciona$\mathrm{les}^{31}$, pues unos y otros son conferidos por normas de la Constitución ${ }^{32}$. Las restricciones indirectamente constitucionales son todas aquellas limitaciones estatuidas por el legislador, en ejercicio de una autorización concedida por una norma constitucional ${ }^{33}$.

De acuerdo con lo expresado, una medida restrictiva de derechos fundamentales sólo puede considerarse teleológicamente idónea, es decir, legítima, si ni ella ni su finalidad están constitucionalmente prohibidas, y si su finalidad es proteger o promover el disfrute de derechos fundamentales, de bienes constitucionales, o de intereses establecidos por el legislador previa autorización de una norma constitucional. Por el contrario, la medida será teleológicamente inidónea, es decir, ilegítima, si la restricción de derechos fundamentales que pretende está constitucionalmente prohibida, o si no favorece el disfrute de derechos fundamentales, de bienes constitucionales o de intereses estatuidos por el legislador autorizado por una norma constitucional ${ }^{34}$.

${ }^{31}$ Para efectos de este trabajo se entiende por bien constitucional a aquel elemento incluido en una norma constitucional que, sin atribuir derechos subjetivos, establece un interés o valor que debe ser alcanzado en el mayor grado posible, dentro de las posibilidades jurídicas y fácticas.

${ }^{32}$ Nogueira Alcalá, Humberto, Dogmática constitucional (Talca, Editorial Universidad de Talca, 1997), p. 282, afirma: "El ejercicio de los derechos fundamentales se concreta en la convivencia societaria, por lo cual los derechos constituyen un asunto de interés individual y, a la vez, comunitario. Los derechos que ejerce cada individuo tienen como límite el respeto al ejercicio de los derechos de los demás miembros de la sociedad, como asimismo los bienes jurídicos que establece el orden constitucional en la perspectiva del bien común".

${ }^{33} \mathrm{El}$ fundamento de las restricciones indirectamente constitucionales es la propia norma constitucional que autoriza al legislador para establecer la respectiva restricción. Así, por ejemplo, el Artículo 19, número 4, dispone que el hogar sólo podrá ser allanado en los casos y formas determinados por la ley. Ahora bien, la finalidad de esa restricción deberá ser determinada en cada caso por el legislador. Esa finalidad no se limita a los derechos fundamentales o a la moral, el orden público o el bien común, como podría desprenderse de lo afirmado por PeCes-BARBA, Gregorio, Derechos fundamentales ( $3^{\mathrm{a}}$ edición, Madrid, Latina Universitaria, 1980), pp. 113-124. Al respecto este autor expone que los derechos fundamentales pueden ser limitados, además de por otros derechos fundamentales, por la moral vigente, el orden público y el bien común. Con todo, y con miras a salvar la opinión de Peces-Barba, se puede decir que a estos tres intereses se puede reconducir prácticamente toda justificación de restricción legislativa de los derechos fundamentales.

${ }^{34}$ Conviene destacar que Prieto SANChÍs, Luis, El juicio de ponderación constitucional, en Alexy, R., y otros, El principio de proporcionalidad en la interpretación constitucional (Santiago de Chile, Librotecnia, 2010), p. 133, discrepa parcialmente del concepto de legitimidad que aquí se ha sugerido. En su opinión para que una medida sea legítima basta que no esté constitucionalmente prohibida. Por tanto, no requiere 
Por otra parte, la medida evaluada puede considerarse técnicamente idónea si es efectivamente adecuada para promover los fines pretendidos con la aplicación de la misma ${ }^{35}$. Estos fines deben consistir, según se explicó recién, en la protección o promoción de otros derechos fundamentales o de bienes constitucionales, o de fines establecidos por el legislador previa autorización constitucional. En consecuencia, la exigencia de idoneidad instrumental se justifica en que la restricción a derechos fundamentales debe ser realmente útil para favorecer tales finalidades ${ }^{36}$. Y es precisamente esa utilidad la que debe ser evaluada por el órgano jurisdiccional, a partir de la información con que cuenta ${ }^{37}$. Por cierto, no es necesario que la medida que se evalúa sea la que mejor permite fomentar la finalidad perseguida, sino que basta que permita fomentarla ${ }^{38}$.

favorecer derechos fundamentales o bienes constitucionales. Al respecto expresa lo siguiente: "En línea de principio, pudiera pensarse que la ponderación se establece entre normas del mismo nivel jerárquico, es decir, entre fines con igual respaldo constitucional, pero creo que en la práctica puede existir una deferencia hacia el legislador, un respeto hacia su autonomía política -que, en verdad, constituye en sí misma un valor constitucional- de manera que se acepten como fines legítimos todos aquellos que no estén prohibidos por la Constitución o resulten abiertamente incoherentes con su marco axiológico".

${ }^{35}$ GonzÁlez Beilfuss, M., cit. (n. 27), p. 16, explica lo que aquí se ha denominado idoneidad técnica como la "aptitud o adecuación de la medida objeto de control para conseguir la finalidad perseguida”.

${ }^{36}$ Como destaca Perello Domenech, I., cit. (n. 27), p. 70, es preciso "que la restricción que sufre el derecho resulte realmente útil para justificar el fin perseguido, o, dicho en negativo, que la medida restrictiva no sea desde todo punto de vista, y en principio, absolutamente inútil para alcanzar el fin”. Prácticamente con las mismas palabras, Vidal Fueyo, C., cit. (n. 11), p. 443, expresa que "es necesario que la limitación que sufre el derecho resulte apropiada para lograr el fin que lo justifica".

${ }^{37}$ En palabras de SÁNCHEZ GIL, R., El principio, cit. (n. 24), pp. 44 y 45, esta evaluación "requiere de un pronóstico del órgano a cuyo juicio está calificar la legitimidad de la medida que interviene un derecho fundamental, por el cual constate que tiene la capacidad suficiente para servir a la obtención del estado de cosas que se propone lograr con ella". Al efecto es suficiente "que los conocimientos técnicos relevantes y la apreciación judicial o legislativa, produzcan la convicción de que ésa será la tendencia natural de dicha medida”.

${ }^{38}$ ClÉRICO, L., cit. (n. 9), pp. 59 y 60, distingue entre una versión fuerte y una versión débil de la relación positiva entre la medida evaluada y el fin perseguido. Al respecto, en lo esencial sostiene que exigir la elección del medio que mejor permite promover el fin (versión fuerte) "se acerca a un ideal. Como los ideales no pueden ser realizados en su completitud, quien aplica y controla el derecho [es decir, el juzgador] no puede razonablemente exigir del actor la elección del medio más adecuado en todos los aspectos". Sin embargo, añade la siguiente precisión: "Esa versión fortísima de la adecuación técnica, ideal, queda como idea regulativa: ésta debe servir de orientación al actor legislativo y en su caso al ejecutivo y a los órganos de control político y a la 
$\mathrm{Si}$, por el contrario, la medida restrictiva de derechos fundamentales no favorece algún derecho fundamental, algún bien constitucional o alguna finalidad establecida por el legislador constitucionalmente delegado, es técnicamente inidónea. Ello se debe a que resulta indiferente para el interés que supuestamente desea favorecer, pero perjudica el disfrute de derechos fundamentales. En consecuencia, se trata de una medida que implica una pérdida en el orden constitucional, sin ofrecer una ganancia en este mismo orden $^{39}$.

Lo recién expuesto muestra que la regla de idoneidad es un juicio relativo a la eficacia de la medida sometida a control. La aplicación de esta regla permite evaluar si la medida constituye un medio adecuado para promover la finalidad perseguida ${ }^{40}$. Por cierto no se trata de un juicio que se mueva en un nivel jurídico, sino de un juicio de carácter fáctico. En efecto, de lo que se trata en este caso es de determinar si, en los hechos, la medida evaluada permite favorecer la finalidad pretendida ${ }^{41}$.

\section{Operaciones para la aplicación de la regla de idoneidad.}

En la práctica, la aplicación de la regla de idoneidad exige realizar cuatro operaciones sucesivas ${ }^{42}$. La primera de ellas consiste en identificar la medida

ciudadanía. Por consiguiente, si bien el operador jurídico debe controlar la adecuación técnica del medio en el marco de una versión débil del referido examen, la versión fortísima no deviene inútil”.

${ }^{39}$ En este mismo sentido expresa Prieto Sanchís, L., cit. (n. 34), p. 134: “Si esa actuación no es adecuada para la realización de lo prescrito en una norma constitucional, ello significa que para esta última resulta indiferente que se adopte o no la medida en cuestión; y entonces, dado que sí afecta, en cambio, a la realización de otra norma constitucional, cabe excluir la legitimidad de la intervención”.

${ }^{40}$ Así lo explica SAPAG, M., cit. (n. 24), p. 186, cuando afirma que la regla de idoneidad constituye "un juicio de eficacia, es decir, el medio de lograr de algún modo la finalidad propuesta.

${ }^{41}$ Esta idea es coherente con lo expresado por Alexy, R., Teoría, cit. (n. 8), pp. 112 y 113, cuando afirma que de lo que él llama máxima de la adecuación se sigue que los principios (es decir, los derechos fundamentales) son mandatos de optimización con relación a las posibilidades fácticas.

${ }^{42} \mathrm{La}$ enunciación de tareas que a continuación se explica coincide parcialmente con la implícitamente descrita por Bernal Pulido, C., Elprincipio, cit. (n. 24), p. 690. Al explicar la aplicación de la regla de idoneidad al evaluar medidas del Legislador, textualmente expresa este autor: "Únicamente si se ha establecido de antemano qué finalidad persigue la intervención legislativa, y si se ha constatado que esta finalidad no resulta ilegítima desde el punto de vista de la Constitución, podrá enjuiciarse si la medida adoptada por el Legislador resulta idónea para contribuir a su realización”. Adviértase que la propuesta de este trabajo establece como tarea previa a todas las recién indicadas la identificación de la medida que será sometida a evaluación. No resulta difícil advertir 
por evaluar. En términos muy concretos, se trata de determinar en qué consiste el mandato, prohibición o permisión expresado en aquella. Si se trata de varias medidas, se las deberá identificar y distinguir claramente, pues el examen de idoneidad se debe realizar respecto de cada una de ellas.

En segundo lugar se debe identificar la finalidad de dicha medida. Al respecto conviene tener presente que la finalidad puede haber sido declarada al fundamentar la medida o encontrarse implícita o incluso oculta. Por otra parte, puede tratarse de una o de varias finalidades. En este último caso deben ser claramente distinguidas, pues el examen de idoneidad también se realiza respecto de cada una de ellas.

La tercera operación es propiamente una evaluación de idoneidad teleológica. Consiste en analizar si la medida restrictiva de derechos fundamentales y su finalidad, si es una, o cualquiera de las finalidades, si son varias, efectivamente promueven un derecho fundamental, un bien constitucional o un interés establecido por el legislador constitucionalmente autorizado ${ }^{43}$. En este tercer paso es necesario distinguir dos posibilidades.

Por una parte, la medida es teleológicamente inidónea si se encuentra constitucionalmente prohibida o si no favorece derechos fundamentales, bienes constitucionales o intereses del legislador constitucionalmente delegado. Y será igualmente inidónea si su finalidad, si es única, o todas sus finalidades, si son varias, son constitucionalmente prohibidas. Frente a esta primera clase de situaciones, no será necesario continuar adelante con el examen de proporcionalidad, pues la medida es inconstitucional.

Por el contrario, la medida es teleológicamente idónea si ni ella ni alguna de sus finalidades se encuentran constitucionalmente prohibidas o si dicha medida promueve un derecho fundamental, un bien constitucional o un interés establecido por el legislador constitucionalmente delegado. En tales casos se debe continuar con el análisis de la idoneidad técnica respecto de la

que dicha tarea es lógicamente anterior a los tres pasos tácitamente referidos por Bernal Pulido en el texto transcrito.

${ }^{43}$ SAPAG, M., cit. (n. 24), p. 189, sugiere distinguir tres cuestiones al evaluar lo que aquí se ha denominado idoneidad teleológica de la medida, las que sintetiza en las siguientes preguntas: ¿cuál es la finalidad? ¿es constitucional? ¿es socialmente relevante? Pues bien, no parece posible coincidir con la sin duda interesante propuesta de Sapag. De un lado, porque la primera de esas preguntas es un supuesto lógico del examen de idoneidad en general y no sólo de la evaluación de idoneidad teleológica. De otro lado, porque la tercera de estas preguntas normalmente se podrá asociar al logro de algún bien constitucional, como la protección de la familia, la integración armónica de todos los sectores de la Nación, el orden público, o cualquier otro expresado en la Constitución. Por el contrario, si la medida no se puede asociar a ningún bien constitucional, lo que parece difícil, entonces no podrá ser incluida en el análisis de proporcionalidad, que es eminentemente jurídico. 
medida teleológicamente idónea. Por cierto las demás finalidades, las que no cumplen este requisito, son teleológicamente inidóneas y, en consecuencia, a su respecto no procede continuar con el examen de proporcionalidad.

Si la medida se considera teleológicamente idónea, se inicia la cuarta tarea. En este caso se trata de una evaluación de idoneidad técnica, en virtud de la cual se determina la coherencia entre medios y fines. En particular se debe analizar si la finalidad se puede alcanzar a través de la medida identificada. Si la medida identificada no es apta para favorecer el disfrute de derechos fundamentales, de bienes constitucionales o de intereses establecidos por el legislador constitucionalmente autorizado, entonces es técnicamente inidónea. Y, como adicionalmente su imposición afecta el disfrute de un derecho fundamental, deberá ser declarada inconstitucional ${ }^{44}$. En caso contrario, habrá superado el examen realizado a la luz de la regla de idoneidad y deberá continuar su análisis bajo las demás reglas. Conviene reiterar que el tribunal que evalúa la idoneidad instrumental de la medida no requiere confirmar que se trata de la medida más eficaz, sino que basta que advierta que la medida permite promover el objetivo perseguido ${ }^{45}$.

\section{Aplicación de la regla de idoneidad a un caso jurisprudencialmente resuelto.}

En lo que sigue se mostrará cómo se aplica la regla de idoneidad al caso de la restricción vehicular en Temuco, relatado al inicio del presente trabajo. Para estos efectos se seguirán los pasos indicados, en el mismo orden en que han sido presentados. Esto significa que: $i$ ) se identificará la medida sometida a control; ii) se determinará el o los fines perseguidos por la misma; iii) se evaluará su idoneidad teleológica; y iv) se analizará su idoneidad técnica.

Para efectos de esta evaluación se debe recordar que el examen de proporcionalidad sólo se aplica si la medida implica la lesión de un derecho fundamental. Pues bien, en este caso la medida afecta los derechos fundamentales a la libertad de trabajo ${ }^{46}$, a la libre iniciativa económica ${ }^{47}$, y a la igualdad ${ }^{48}$.

${ }^{44}$ Alexy, Teoría, cit. (n. 8), p. 114, explica esta consecuencia del siguiente modo: si la medida no es adecuada para la promoción u obtención de la finalidad que viene exigida por un determinado derecho fundamental, entonces esa medida no es exigida por este derecho fundamental.

${ }^{45}$ Con acierto afirma SÁNCHez Gil, R., El principio, cit. (n. 24), p. 44, que la regla de idoneidad "no tiene por objeto provocar una excesiva intervención de la judicatura constitucional en la labor del legislador”. Por ello, no se debe evaluar si es la más eficaz, sino que "es bastante con que la medida que interviene los derechos fundamentales, ayude o coopere de algún modo a la realización del fin” pretendido..

${ }^{46}$ Artículo $19 \mathrm{~N}^{\circ} 16$ C.PolCh.

${ }^{47}$ Artículo $19 \mathrm{~N}^{\circ} 21$ C.PolCh.

${ }^{48}$ Artículo $19 \mathrm{~N}^{\circ} 2$ C.PolCh. 
i) Identificación de la medida sometida a control. La medida sometida a evaluación se expresa en la Resolución exenta $N^{\circ}$ 95, de la Secretaría Regional Ministerial de Transportes y Telecomunicaciones de la Región de la Araucanía, de 28 de febrero de 2008. Dicha medida consistió en prohibir la circulación de lunes a viernes, entre 7:00 y 22:00 horas, de taxis colectivos dentro de la comuna de Temuco, de acuerdo al último dígito de su placa patente y a razón de dos dígitos por día, siempre que estuvieren prestando servicios de taxi colectivo, a partir del 3 de marzo del 2008.

ii) Identificación de las finalidades de la medida sometida a control. Según se declaró en la misma resolución, las finalidades de esa medida fueron dos. Primero, disminuir la contaminación ambiental que afecta a las ciudades de Temuco y Padre Las Casas. Segundo, disminuir la congestión vehicular que se produce en la zona centro de la comuna de Temuco.

iii) Evaluación de idoneidad teleológica de la medida. La pretensión de disminuir la contaminación ambiental en las ciudades de Temuco y Padre Las Casas es, claramente, una finalidad legítima. Se trata de una intención que busca proteger y promover el derecho fundamental a vivir en un medioambiente libre de contaminación, al que se refiere el artículo 19, $\mathrm{N}^{\circ} 8 \mathrm{C}$.Pol. En consecuencia, esta finalidad supera el examen de idoneidad teleológica. Corresponde, por tanto, evaluar su idoneidad instrumental.

La pretensión consistente en disminuir la congestión vehicular, por su parte, es también una finalidad legítima. Para comprender esta afirmación es necesario tener presente que el derecho fundamental a la libertad de movimiento (o de tránsito) debe ejercerse respetando las normas establecidas en la ley ${ }^{49}$. Y, además, se debe considerar que el derecho fundamental a la libre actividad económica se debe desarrollar respetando las normas que la regulen ${ }^{50}$. Ahora bien, resulta posible entender que el inciso segundo del artículo $3^{\circ}$ de la ley 18.696 es expresión de las normas a que se refieren ambos derechos fundamentales. En dicha disposición se prescribe, en lo pertinente, que el Ministerio de Transportes y Telecomunicaciones podrá, en los casos de congestión de las vías, disponer el uso de las vías para determinados tipos de vehículos y/o servicios ${ }^{51}$. Por tanto, se trata de una finalidad legítima,

${ }^{49}$ Artículo $19 \mathrm{~N}^{\circ} 7$, letra a) C.PolCh.

${ }^{50}$ Artículo $19 \mathrm{~N}^{\circ} 21$ inciso $1^{\circ} \mathrm{C}$.PolCh.

${ }^{51}$ El texto completo del inciso $2^{\circ}$ del artículo 3 de la Ley $\mathrm{N}^{\circ} 18.696$, dispone lo siguiente: "El Ministerio de Transportes y Telecomunicaciones, sin perjuicio de lo dispuesto en el Artículo $118^{\circ}$ de la ley 18.290, podrá, en los casos de congestión de las vías, de deterioro del medio ambiente y/o de las condiciones de seguridad de las personas o vehiculos producto de la circulación vehicular, disponer el uso de las vias para determinados tipos de vehiculos y/o servicios, mediante procedimientos de licitación pública, para el funcionamiento del mercado de transporte de pasajeros". 
consistente en una restricción indirectamente constitucional.

iv) Evaluación de idoneidad técnica de la medida. La medida de restricción vehicular no supera el examen de idoneidad técnica debido a que no presenta coherencia con la finalidad de disminuir la congestión vehicular ni con la finalidad de favorecer un medioambiente libre de contaminación. Al respecto es necesario tener presente ciertas consideraciones de hecho.

Es efectivo que en las ciudades de Temuco y Padre Las Casas existe un problema de contaminación. Sin embargo, el $87 \%$ de la contaminación atmosférica de tales ciudades proviene de emisiones residenciales, específicamente del sistema de calefacción a leña, un 7\% de las industrias y sólo un $1,1 \%$ de la circulación de vehículos motorizados. Luego, el impacto de los aproximadamente 250 taxis colectivos a los que afectaría la restricción vehicular cada día representaba un $0,005 \%$ sobre el total de la contaminación atmosférica. Pero además, y según se ha señalado, la medida administrativa sólo afectaba a los taxis colectivos que estuvieran en servicio, pero no les impedía circular en forma particular ${ }^{52}$.

También es efectivo que en Temuco se produce congestión vehicular en determinados días y horas. Sin embargo, en esta ciudad existían 42.000 vehículos a la fecha de la medida cuestionada. De ellos, 1.410 eran taxis colectivos, lo que representaba el 3,2\% del parque automotriz. Luego la restricción vehicular afectaba al $20 \%$ de tales vehículos, lo que a su turno representaba el 0,64\% del total de vehículos de Temuco. Pero además, y según se ha dicho reiteradamente, la medida sólo impedía que los vehículos prestaran el servicio de taxis colectivos, pero no les impedía circular en forma particular ${ }^{53}$.

${ }^{52} \mathrm{La}$ Corte de Apelaciones de Temuco con singular acierto recogió esta incoherencia entre medio (restricción vehicular) y fines (descontaminación atmosférica) en el considerando $7^{\circ}$ de la sentencia de 25 de abril de 2008, recaída en la causa rol $\mathrm{N}^{\circ} 300$ 2008, sobre recurso de protección, al expresar: "Finalmente, en relación a la necesidad de descontaminar el aire de la ciudad, la resolución no resiste menor análisis, en primer término, porque la incidencia de las emisiones contaminantes de los taxis colectivos es infima en relación a otros que sí tienen incidencia crucial y, en segundo lugar, porque si lo que realmente querido fuere evitar la circulación de fuentes contaminantes, la restricción hubiera sido total y no se habría permitido la circulación de los mismos taxis sin pasajeros". La Corte Suprema, por su parte, nada dijo respecto de esta incoherencia.

${ }^{53}$ En similar sentido razonó la Corte de Temuco al expresar en el considerando $7^{\circ}$ de la sentencia de 25 de abril de 2008 , recaída en la causa rol $\mathrm{N}^{\circ} 300-2008$, sobre recurso de protección que "el argumento de la congestión vehicular no pasa el umbral de lo equitativo, puesto que no se puede entender que si lo que se pretende por la autoridad es atacar la congestión vehicular en las calles céntricas de Temuco, no se haya dispuesto una restricción a todo el transporte público y, en general a todo vehiculo motorizado, considerando el parque automotriz que se ha dicho que posee Temuco. Las preguntas surgen inmediatamente: ¿por qué los buses no están afectos? ¿por qué si tienen restricción para operar comercialmente un determinado día, pueden circular como vehiculos particulares?" 
Lo recién expresado muestra que la medida sometida a control carece de conexión lógica con la finalidad pretendida. Esto significa que, en los hechos, la restricción vehicular no favorece el disfrute de algún derecho fundamental o de algún bien constitucional. Tan evidente incoherencia permite concluir que la medida es inidónea desde el punto de vista técnico.

Habiéndose verificado que ninguna de las dos finalidades de la resolución exenta de la Secretaría Regional Ministerial de Transportes y Telecomunicaciones supera el examen a la luz de la regla de idoneidad, resulta posible concluir que se trata de una medida inconstitucional. En consecuencia, no resulta pertinente continuar su examen bajo las reglas de necesidad y ponderación.

\section{LA REGLA DE NECESIDAD}

\section{Significado de la regla de necesidad.}

La regla de necesidad evalúa la constitucionalidad de una medida restrictiva de derechos fundamentales en dos niveles. En primer lugar, se debe determinar si la medida sometida a control es la única idónea para favorecer la finalidad pretendida con su aplicación, lo que aquí se denominará necesidad teleológica. En segundo lugar, se debe analizar si dicha medida es la que implica una menor afectación en los derechos fundamentales, lo que aquí se denominará necesidad técnica. Si la medida es la única idónea se habrá superado el estándar establecido por esta segunda regla, y lo mismo ocurrirá si es la que menos afecta los derechos fundamentales, ${ }^{54}$.

De acuerdo con lo recién explicado, la medida sometida a control es te-

${ }^{54}$ Bernal Pulido, C., El principio, cit. (n. 24), pp. 737 y 738, explica estas dos exigencias, pero desde el punto de vista de los posibles medios alternativos a la medida evaluada. Al efecto expresa que la regla de necesidad implica la comparación entre la medida evaluada y otros medios alternativos. "En esta comparación, añade el autor, se examina si alguno de los medios alternativos logra cumplir dos exigencias: en primer lugar, si reviste por lo menos el mismo grado de idoneidad que la medida [evaluada para] (...) alcanzar el objetivo inmediato de esta última; y, en segundo lugar, si afecta negativamente al derecho fundamental en un grado menor". GonZÁleZ BeILfuss, M., cit. (n. 27), p. 18, se refiere a ambas exigencias bajo las fórmulas de "ausencia de alternativas más moderadas (o menos gravosas) para la consecución, con igual eficacia, de la finalidad perseguida". En fin, similar perspectiva se puede encontrar en VIDAL Fueyo, C., cit. (n. 11), p. 443, pues el autor denomina de indispensabilidad la regla en análisis. El Tribunal Constitucional español, por su parte, ha consolidado su comprensión de la regla de necesidad en el sentido que con él se evalúa si la medida "es necesaria, en el sentido de que no exista otra medida más moderada para la consecución de tal propósito con igual eficacia (juicio de necesidad)" (sentencia 168/2000, de 10 de julio de 2000, fundamento jurídico 6, párrafo quinto). 
leológicamente necesaria si es la única idónea. Esto significa que no existen alternativas al menos igualmente eficaces para favorecer los fines perseguidos con su imposición ${ }^{55}$. Para arribar a una tal conclusión es necesario preguntarse si existen medios alternativos que revistan igual idoneidad y responder a este problema de manera negativa ${ }^{56}$. De este modo, y como se puede advertir, la evaluación de necesidad teleológica de la medida tiene carácter comparativo ${ }^{57}$. Lo que aquí se compara es el grado de idoneidad de la medida sometida a control y medidas alternativas, pues estas últimas deben presentar al menos la misma capacidad que la primera para promover el fin buscado ${ }^{58}$.

Por otra parte, la medida sometida a control es técnicamente necesaria si es la que importa una menor injerencia en el disfrute de los derechos fundamentales. Dicho de otro modo, debe tratarse de la más suave o moderada de entre las que permiten alcanzar la finalidad pretendida ${ }^{59}$. Para llegar a una tal conclusión es necesario preguntarse si la medida controlada es la que menos afecta derechos fundamentales y responder a este problema de manera positiva ${ }^{60}$. Adviértase que este nivel de análisis tiende a optimizar el disfrute de los derechos fundamentales, pues rechaza aquellas medidas que pueden ser reemplazadas por otras igualmente eficaces, pero menos lesivas ${ }^{61}$. En

${ }^{55}$ En este sentido González Beilfuss, M., cit. (n. 27), p. 18, afirma que la necesidad de la medida significa, en este primer nivel, la ausencia de alternativas para la consecución, con igual eficacia, de la medida perseguida.

${ }^{56}$ Asíl lo sostiene Bernal Pulido, C., Elprincipio, cit. (n. 24), pp. 737 y 738, cuando explica que en este primer nivel se examina si alguno de los medios alternativos reviste por lo menos el mismo grado de idoneidad que la medida evaluada para alcanzar el objetivo inmediato de esta última.

${ }^{57} \mathrm{Al}$ respecto Rojas, I. Y., cit. (n. 16), p. 8, sostiene que la regla de necesidad "puede ser considerado un principio comparativo debido a que, a diferencia de los principios de idoneidad y de proporcionalidad en sentido estricto, no limita el examen de la admisibilidad de la medida únicamente al estudio de su contenido, efectos y fines, sino que induce al órgano actuante a la búsqueda de medidas alternativas idóneas". Aunque la autora atribuye esta característica a todo la regla de necesidad, lo que expresa sólo resulta aplicable a lo que aquí se ha denominado necesidad teleológica.

${ }^{58} \mathrm{Al}$ listar los casos en los que la medida sería inidónea SÁNCHEZ GIL, R., El principio, cit. (n. 24), p. 45, explica que la comparación debe hacerse "entre diversas opciones igualmente idóneas para conseguir el fin mencionado".

${ }^{59}$ Perello Domenech, I., cit. (n. 27), p. 70, sostiene que la medida sometida a control "debe ser la más moderada entre todos los medios útiles", esto es, "no hay otra más suave o moderada”.

${ }^{60}$ ClériCO, L., cit. (n. 9), p. 101, formula esta misma pregunta en los siguientes términos: “`se puede evitar la restricción del derecho a través de otro medio, o por lo menos, reducir el grado de limitación?” Y añade: "La respuesta a este segundo interrogante presupone una comparación entre medios. Esta comparación constituye el núcleo del examen del medio alternativo menos gravoso".

${ }^{61}$ Rojas, I. Y., cit. (n. 16), p. 8, expresa esta idea respecto de la regla de necesidad 
consecuencia, la evaluación de necesidad técnica también tiene carácter comparativo entre la medida sometida a control y medios igualmente idóneos, pero ahora respecto del grado en que afectan derechos fundamentales ${ }^{62}$.

De acuerdo con estas explicaciones, mientras la regla de idoneidad constituye un juicio relativo a la eficacia de la medida evaluada (capacidad para alcanzar la finalidad), la regla de necesidad es un juicio relativo a la eficiencia de la misma (capacidad para generar el menor costo en la consecución de la finalidad $)^{63}$.

\section{Exámenes para la aplicación de la regla de necesidad.}

No es lógicamente posible aplicar la regla de necesidad sin haber realizado, previamente, las mismas operaciones exigidas por la regla de adecuación. Ello se debe a que la identificación de la medida y de su finalidad, así como la evaluación de idoneidad teleológica y técnica de la medida sometida a control son condición de posibilidad de la aplicación de la regla de necesidad. Sobre tales identificaciones y evaluaciones, la aplicación de la medida bajo la regla de necesidad exige cumplir cuatro exámenes en forma sucesiva.

a) El primer examen consiste en esclarecer si existen otros medios idóneos para favorecer la finalidad perseguida con la medida limitativa de derechos fundamentales. Este es un verdadero juicio de idoneidad teleológica respecto de cada uno de los medios alternativos identificados. Si no existen otros medios, se trata de una medida necesaria, pues no existe otra

en general, cuando afirma que "es un principio que tiende a la optimización del grado de eficacia de los derechos fundamentales limitados porque obliga a rechazar las medidas que puedan ser sustituidas por otras menos gravosas, mecanismo mediante el cual disminuye la lesividad de la intromisión en la esfera de derechos y libertades del individuo". Sin embargo, esta optimización sólo puede predicarse del juicio de necesidad técnica. En efecto, es este el nivel en el cual se compara la afectación de derechos fundamentales por parte de los diversos medios idóneos. El juicio de necesidad teleológica, en cambio, se limita a considerar la aptitud de la medida sometida a control y de los medios alternativos respecto del fin.

${ }^{62}$ En palabras de Prieto Sanchís, L., cit. (n. 34), p. 135: "Ello significa que si la satisfacción de un bien constitucional puede alcanzarse a través de una pluralidad de medidas o actuaciones, resulta exigible escoger aquella que menos perjuicios cause desde la óptica del otro principio o derecho en pugna". En similar sentido se pronuncia Perello Domenech, I., cit. (n. 27), p. 71, al expresar que esto implica "confrontar los diversos medios igualmente idóneos y aptos para la consecución del fin, y determinar aquélla que resulte menos onerosa”. añade la autora, en la misma página, que, "por consiguiente, han de rechazarse las medidas más gravosas y elegir el medio más beneficioso".

${ }^{63}$ En este sentido se expresa SAPAG, M., cit. (n. 24), p. 187, cuando explica que, de acuerdo con la regla de necesidad, si "existen otras medidas más eficientes, la implementada no superará este juicio y deberá ser declarada inconstitucional”. 
que pueda reemplazarla. En consecuencia, con esta verificación ha cesado la evaluación a la luz de la regla de necesidad y deberá continuar su análisis bajo la regla de ponderación ${ }^{64}$. Si, por el contrario, existen medidas alternativas que permiten fomentar el fin pretendido, se debe continuar el análisis con el segundo examen.

b) En virtud de él se debe determinar si los medios alternativos idóneos son al menos igualmente eficaces que la medida sometida a control para promover la finalidad perseguida. Se trata de un juicio de comparación entre la oportunidad e intensidad con que permiten alcanzar la finalidad tanto la medida sometida a control como los medios alternativos que se han considerado idóneos. Pues bien, si los medios alternativos permiten alcanzar la finalidad, pero en forma tardía o en menor grado que la medida evaluada, esta última es necesaria porque no hay otra que pueda reemplazarla con igual eficacia ${ }^{65}$. En otras palabras, la medida enjuiciada es teleológicamente necesaria. Con esta constatación ha cesado la evaluación a la luz de la regla de necesidad y deberá continuar su análisis bajo la regla de ponderación. Si, por el contrario, uno o más de los medios alternativos es tanto o más adecuado para lograr la finalidad perseguida con la medida, entonces la medida sometida a control no es teleológicamente necesaria. En consecuencia, se debe proceder a realizar el tercer examen ${ }^{66}$.

c) El tercer examen consiste en identificar la intensidad en que limitan los derechos fundamentales tanto la medida sometida a control, como las demás que se consideran al menos igualmente eficaces. En este caso se mide por separado el grado de afectación de derechos fundamentales que genera cada una de las alternativas. Como se puede advertir, este paso no permite tomar decisiones respecto de la medida evaluada, sino sólo preparar el siguiente examen en la aplicación de la regla de necesidad.

d) En virtud del cuarto examen se deben comparar los grados de afectación de derechos fundamentales que generan las diversas medidas igualmente idóneas para alcanzar la finalidad perseguida. Si la medida sometida a control es la menos lesiva, entonces es necesaria, pues no existe otra más favorable que

${ }^{64}$ Sánchez GIL, R., El principio, cit. (n. 24), p. 45, sostiene que uno de los casos en que la medida sometida a control cumple con la regla de necesidad consiste en que aquella es indispensable porque "no existen opciones para satisfacer el fin perseguido".

${ }^{65}$ Esta posibilidad es explicada por Clérico, L., cit. (n. 9), p. 104, del siguiente modo: "Cuando el medio alternativo no fomenta el fin tan bien como el medio establecido, entonces el medio establecido queda como necesario (es decir, como el menos gravoso)".

${ }^{66}$ De acuerdo con Clérico, L., cit. (n. 9), p. 104: “Cuando el medio alternativo fomenta el fin tan bien como el medio establecido, entonces hay que probar el medio alternativo para determinar si es el menos gravoso en sentido estricto", es decir, si resulta menos lesivo para los derechos fundamentales. 
pueda reemplazarla ${ }^{67}$. Dicho con mayor precisión, es técnicamente necesaria. En este punto concluye la evaluación de la medida sometida a control a la luz de la regla de necesidad y deberá continuar su análisis bajo la regla de ponderación. Si, por el contrario, alguno de los medios alternativos implica menor limitación a los derechos fundamentales que la medida evaluada, entonces esta última es innecesaria ${ }^{68}$. Ello se debe a que se puede lograr la misma finalidad constitucionalmente legítima con un menor costo para tales derechos. Y, como consecuencia, es una medida inconstitucional ${ }^{69}$.

${ }^{67}$ Esta idea es expresada por CLÉRICO, L., cit. (n. 9), p. 114, en los siguientes términos: "Si hay medios alternativos, y su implementación puede fomentar el fin, y si cada uno de esos medios (o algunos de ellos o por lo menos uno) pueden hacerlo en igual o parecida medida en comparación con el medio establecido, y si la implementación de los medios alternativos restringe en igual o mayor medida los principios iusfundamentales u otros constitucionales (o cargan en igual o mayor medida a la persona afectada) que a través del medio establecido, entonces la medida estatal queda como la menos lesiva”. En el mismo sentido, SÁNCHEZ GIL, R., El principio, cit. (n. 24), p. 45, expone que el otro caso en que la medida evaluada cumple con la regla de necesidad consiste en que aquella es indispensable porque "es la menos gravosa para el derecho afectado, entre diversas opciones igualmente idóneas para conseguir el fin mencionado”. El autor reitera esta idea inmediatamente, aunque presentándola como una idea distinta, cuando afirma que esta indispensabilidad de la medida evaluada se confirma si las opciones disponibles para satisfacer el fin perseguido "afectan el derecho intervenido en una medida mayor".

${ }^{68}$ En palabras de Clérico, L., cit. (n. 9), p. 114: "Si hay medios alternativos, y su implementación puede fomentar el fin, y si cada uno de esos medios (o algunos de ellos o por lo menos uno) pueden hacerlo en igual o parecida medida que el medio establecido, y si la implementación de los medios alternativos restringe en menor medida los principios iusfundamentales u otros constitucionales (o carga menos a la persona afectada) que a través del medio establecido, entonces la medida estatal no es proporcional en sentido amplio".

${ }^{69}$ Alexy,Teoría, cit. (n. 8), pp. 113-114, explica esta conclusión bajo lo que denomina "la constelación más simple de un examen de necesidad". Y añade: "La constelación más simple está caracterizada porque en ella están en juego sólo dos principios y dos sujetos jurídicos (Estado/ciudadano)". En este escenario, la caracterización presentada por el autor alemán, adaptada a la nomenclatura utilizada en este trabajo, es la siguiente: el Estado fundamenta la prosecución del fin pretendido con un determinado derecho fundamental. Además, existen, por lo menos, dos medios, la medida evaluada y la opción alternativa, que son igualmente adecuados para lograr o promover la finalidad. Elmedio alternativo afecta menos intensamente que la medida evaluada, o no afecta en absoluto, la realización de aquello que exige otra norma iusfundamental con carácter de principio (el derecho fundamental afectado con la medida). Bajo estos presupuestos, para el derecho fundamental que se pretende promover con la finalidad perseguida es igual que se elija la medida evaluada o el medio alternativo. Sin embargo, para el derecho fundamental afectado no da igual cuál de las opciones se elija. Desde el punto de vista de la optimización con respecto a las posibilidades fácticas, concluye Alexy, bajo 


\section{Aplicación de la regla de necesidad a un caso judicialmente resuelto.}

A continuación se aplicará la regla de necesidad al caso del uso de cámaras de seguridad instaladas por una empresa de Puerto Montt en la sala de procesos en la que los trabajadores prestan servicios para el seguimiento de algunos de ellos que tenían la calidad de dirigentes sindicales. Con tal fin se seguirán cada uno de los exámenes explicados, lo que significa confirmar que se ha superado la regla de adecuación, para luego determinar si la medida supera el examen impuesto por la regla de necesidad.

Como el principio de proporcionalidad sólo puede ser aplicado si la medida evaluada lesiona derechos fundamentales, corresponde precisar cuáles son los en tal sentido involucrados. En el caso de las cámaras de vigilancia ubicadas en la sala de procesos en que los trabajadores prestan servicios y utilizadas para realizar seguimientos a algunos trabajadores que son dirigentes sindicales, los derechos afectados son la libertad sindical ${ }^{70} \mathrm{y}$ la vida privada ${ }^{71}$.

a) Aplicación de la regla de adecuación. La aplicación de la regla de adecuación incluye las siguientes operaciones:

i) Identificación de la medida sometida a control. La medida sometida a control consistió en la decisión de una empresa de utilizar las cámaras de seguridad instaladas en las salas de proceso en las que los trabajadores prestan servicios para realizar seguimientos a algunos de ellos que tenían la calidad de dirigentes sindicales ${ }^{72}$. Debe advertirse que la medida evaluada no es la instalación de las cámaras, sino el haberse utilizado en ciertos momentos para el seguimiento de trabajadores determinados.

ii) Identificación de las finalidades de la medida sometida a control. Según la empresa contra la cual se dedujo la acción de protección, la medida es manifestación del ejercicio de la facultad de dirección de la empresa por el empleador, quien instaló las cámaras y realizó los seguimientos con cuatro finalidades: proteger el establecimiento, proteger el proceso productivo, proteger a los trabajadores y proteger la salud de los consumidores de los productos elaborados por la empresa ${ }^{73}$.

el presupuesto de la validez tanto del derecho fundamental que se desea promover con la finalidad señalada como del derecho fundamental afectado, sólo el medio alternativo está permitido, mientras que la medida sometida a control está prohibida.

${ }^{70}$ Artículo $19 \mathrm{~N}^{\circ} 19$ C.PolCh.

${ }^{71}$ Artículo $19 \mathrm{~N}^{\circ} 4$ C.PolCh.

${ }^{72}$ Sentencia de la Corte de Apelaciones de Puerto Montt de 30 de septiembre de 2005, recaída en la causa rol $N^{\circ} 156-2005$, sobre recurso de protección, considerando tercero.

${ }^{73}$ En la sentencia de la Corte de Apelaciones de Puerto Montt de 30 de septiembre de 2005, recaída en la causa rol $N^{\circ} 156-2005$, sobre recurso de protección, considerando tercero, se deja constancia que la empresa argumentó que "la principal finalidad buscada por el empleador, se orienta a controlar especialmente la seguridad de las personas y 
iii) Evaluación de idoneidad teleológica de la medida. Las cuatro finalidades perseguidas con la medida son legítimas. Esto significa que con cada una de ellas se pretende proteger o promover un derecho fundamental o un bien jurídico constitucional. En efecto, la finalidad consistente en proteger al establecimiento cautela el derecho fundamental de propiedad ${ }^{74}$. La finalidad de proteger el proceso productivo, por su parte, tutela el derecho fundamental a la libre iniciativa económica ${ }^{75}$. La finalidad de proteger a los trabajadores, a su turno, es manifestación del derecho fundamental a la vida y a la integridad física y síquica ${ }^{76}$. Por último, la finalidad de proteger la salud de los consumidores cautela el derecho fundamental a la salud ${ }^{77}$.

iv) Evaluación de idoneidad técnica de la medida. La medida que se enjuicia resulta adecuada para proteger las finalidades legítimas consistentes en proteger al establecimiento, al proceso productivo, a los trabajadores y al establecimiento.

Lo hasta aquí constatado no significa que la medida aplicada por la empresa de utilizar las cámaras de seguridad instaladas en la sala de procesos en que los trabajadores prestan servicios para realizar seguimiento a ciertos trabajadores que eran dirigentes sindicales es constitucional. Sólo significa que ha superado el control ha que ha sido sometida bajo la regla de idoneidad. Corresponde, por tanto, evaluar si es una medida necesaria.

b) Aplicación de la regla de necesidad. De acuerdo con lo expresado más arriba, para evaluar la medida de que se viene tratando bajo la regla de necesidad se debe proceder de la siguiente manera:

i) Identificación de medios alternativos. Las finalidades consistentes en proteger el establecimiento, proteger el proceso productivo, proteger a los trabajadores y proteger la salud de los consumidores de los productos elaborados por la empresa pueden ser alcanzados mediante las mismas cámaras de seguridad, pero utilizadas para presentar visiones generales o panorámicas de la sala de procesos. En consecuencia, existe un medio alternativo para alcanzar las mismas finalidades.

ii) Evaluación de necesidad teleológica. La medida consistente en utilizar las cámaras de vigilancia para presentar visiones generales o panorámicas de la sala de proceso permite advertir posibles maniobras tendientes a dañar el establecimiento, el proceso productivo, a los demás trabajadores o a los

del establecimiento, asi como del proceso productivo de una empresa que elabora productos de consumo humano, por lo que las normas laborales deben compatibilizar con las normas de salubridad y protección de la salud y vida de los consumidores de sus productos".

${ }^{74}$ Artículo $19 \mathrm{~N}^{\circ} 24$ C.PolCh.

${ }^{75}$ Artículo $19 \mathrm{~N}^{\circ} 21$ C.PolCh.

${ }^{76}$ Artículo $19 \mathrm{~N}^{\circ} 1 \mathrm{C}$.PolCh.

${ }^{77}$ Artículo $19 \mathrm{~N}^{\circ} 9$ C.PolCh. 
productos. En consecuencia, permite asegurar las cuatro finalidades en igual oportunidad y con igual intensidad que la medida de seguimiento de trabajadores. Por tanto, utilizar las cámaras de vigilancia para realizar seguimientos no es teleológicamente necesario. Al no serlo, resulta necesario evaluar cuál de las medidas (la que se ha aplicado o la alternativa) resulta menos lesiva de los derechos fundamentales. Para ello se realizan los dos siguientes pasos.

iii) Identificación del grado de afectación de derechos fundamentales. La medida sometida a enjuiciamiento puede afectar el derecho fundamental a la libertad sindical y el derecho fundamental a la vida privada de los mismos. El primero porque el seguimiento de dirigentes sindicales mediante las cámaras de vigilancia permite controlar sus actuaciones y restar autonomía al accionar de los mismos y de la organización sindical en su conjunto. El segundo porque el derecho a la vida privada de los trabajadores no se limita a los baños y vestuarios, sino que también alcanza los lugares en que se prestan los servicios cuando mediante ciertas acciones se accede a información privada de los trabajadores ${ }^{78}$. La medida alternativa, en cambio, no lesiona ningún derecho fundamental. Esto se debe a que una panorámica del lugar de trabajo no permite capturar imágenes que conduzcan a enterarse de información privada del trabajador ${ }^{79}$.

iv) Comparación de los grados de afectación de derechos fundamentales. Según se ha mostrado en el paso anterior, el uso de las cámaras de vigilancia instaladas en la sala en que se prestan los servicios para realizar seguimientos a determinados trabajadores que son dirigentes sindicales puede lesionar los

${ }^{78}$ En este mismo sentido, el Tribunal Constitucional español ha sostenido en la sentencia 98/2000, de 10 de abril de 2000 , fundamento jurídico $6^{\circ}$, que es un error "afirmar que el centro de trabajo no constituye por definición un espacio en el que se ejerza el derecho a la intimidad por parte de los trabajadores". Y ha precisado luego que: "En efecto, si bien hemos afirmado en alguna ocasión que los hechos referidos a las relaciones sociales y profesionales en que el trabajador desempeña su actividad no se integran, en principio, en la esfera privada de la persona (SSTC 180/1987, de 12 de noviembre, FJ 4; 142/1993, de 22 de abril, FJ 7 y 202/1999, de 8 de noviembre, FJ 2; ATC 30/1998, de 28 de enero, FJ 2), no es menos cierto que también hemos matizado esa afirmación inicial señalando que no cabe ignorar que, mediante un análisis detallado y conjunto de esos hechos, es factible en ocasiones acceder a informaciones atinentes a la vida intima y familiar del trabajador (SSTC 142/1993, FJ 8 y 202/1999, FJ 2), que pueden resultar lesivas del derecho a la intimidad personal protegido por el artículo 18.1 CE".

${ }^{79} \mathrm{Al}$ respecto la Dirección del Trabajo en el Ordinario No 2210/035, de 10 de julio de 2009, apartado III. c, ha dictaminado lo siguiente: "En particular, la instalación y empleo por el empresario de instrumentos de control de la actividad laboral en el centro de trabajo (grabación de sonido, circuito cerrado de televisión) se acomoda a las exigencias del derecho a la intimidad de los trabajadores afectados tan sólo cuando la medida resulte justificada, idónea para la finalidad perseguida por la empresa, necesaria y equilibrada". 
derechos fundamentales a la libertad sindical y a la vida privada de los mismos. La medida consistente en utilizar la misma cámara para presentar visiones generales del lugar de trabajo no lesiona estos derechos. Esto significa que existe un medio alternativo para cumplir las mismas cuatro finalidades, pero sin costo alguno para el derecho fundamental a la vida privada. En consecuencia, la primera de estas medidas, que es la aquí evaluada, es técnicamente innecesaria y, por lo mismo, inconstitucional.

\section{LA REGLA DE PONDERACIÓN}

\section{Significado de la regla de ponderación.}

La regla de ponderación enjuicia la constitucionalidad de la medida sometida a control, mediante una decisión respecto de cuál de los intereses constitucionales que colisionan en el caso debe preceder al otro. Decidir que la medida es constitucional significa preferir los derechos fundamentales o los bienes constitucionales favorecidos por la medida. Decidir que la medida es inconstitucional, por el contrario, implica preferir los derechos fundamentales afectados por la misma.

El problema se solucionaría fácilmente si existiera una precedencia absoluta entre los derechos fundamentales o entre estos y los bienes constitucionales. Sin embargo, no existe tal precedencia, es decir, derechos fundamentales o bienes constitucionales que tengan preeminencia bajo cualquier circunstancia respecto de otros derechos fundamentales o de otros bienes constitucionales $^{80}$. Y ello porque no existen derechos absolutos ${ }^{81}$, ni bienes

${ }^{80}$ Alexy, Teoría, cit. (n. 8), p. 106, justifica el rechazo a la existencia de derechos fundamentales o bienes constitucionales absolutos del siguiente modo: "Es fácil argumentar en contra de la validez de principios absolutos en un ordenamiento jurídico que reconoce derechos fundamentales. Los principios pueden referirse a bienes colectivos o a derechos individuales. Cuando un principio se refiere a bienes colectivos y es absoluto, las normas de derecho fundamental no pueden fijarle ningún límite jurídico. Por lo tanto, hasta donde llegue el principio absoluto, no pueden haber derechos fundamentales. Cuando el principio absoluto se refiere a derechos individuales, su falta de limitación jurídica conduce a la conclusión de que, en caso de colisión, los derechos de todos los individuos fundamentados por el principio tienen que ceder frente al derecho de cada individuo fundamentado por el principio, lo que es contradictorio. Por lo tanto, vale el enunciado según el cual los principios absolutos o bien no son conciliables con los derechos individuales o bien sólo lo son cuando los derechos individuales fundamentados por ellos no corresponden a más de un solo sujeto jurídico".

${ }^{81}$ En este sentido se han pronunciado, por ejemplo, tanto el Tribunal Constitucional español como la Corte Constitucional colombiana. El primero ha sostenido en la sentencia 98/2000, de 10 de abril de 2000, fundamento jurídico 5, que "Igualmente es doctrina reiterada de este Tribunal que "el derecho a la intimidad no es absoluto, como no lo es ninguno de los derechos fundamentales, pudiendo ceder ante intereses constitucional- 
constitucionales absolutos ${ }^{82}$.

Lo anterior significa que la colisión entre los intereses constitucionales favorecidos y perjudicados por la medida evaluada debe ser resuelta bajo un criterio distinto de la precedencia absoluta. Siguiendo a Alexy, ese criterio es el de la precedencia condicionada. La relación de precedencia condicionada "consiste en que, tomando en cuenta el caso, se indican las condiciones bajo las cuales un principio precede al otro. Bajo otras condiciones, la cuestión de la precedencia puede ser solucionada inversamente" 83 .

Para aplicar el criterio de la precedencia condicionada es necesario realizar una ponderación ${ }^{84}$. Realizar una ponderación significa evaluar, a partir de las circunstancias del caso concreto, el peso de cada uno de los intereses constitucionales favorecidos y perjudicados por la medida ${ }^{85}$. Al efecto es necesario Determinar el peso de cada uno de esos intereses constitucionales en el caso concreto, es decir, precisar qué se gana y qué se pierde con la aplicación de la medida sometida a control. Y ello con la finalidad de comparar aquello que se obtiene desde el punto de vista de los derechos fundamentales o de los bienes constitucionales favorecidos con la medida sometida a control y aquello que se sacrifica desde el punto de vista de los derechos fundamentales perjudicados con la misma bajo las condiciones del caso a resolver ${ }^{86}$. $\mathrm{Al}$ efecto es necesario tener presente que "cuanto mayor sea la afectación

mente relevantes". En igual dirección, en la sentencia T-689, de 1 de octubre de 2009, la Corte Constitucional colombiana rechazó la existencia de derechos fundamentales absolutos cuando declaró lo siguiente: "A pesar del amplio alcance que caracteriza la autonomia universitaria y de su indudable relevancia constitucional, esta Corporación ha aclarado que no se trata de un principio con carácter absoluto pues, como ocurre con todos los principios constitucionales, se encuentra sujeto a limites impuestos por el respeto a otros principios constitucionales y por las posibilidades fácticas de su realización”.

${ }^{82}$ Aludiendo tanto a los derechos fundamentales como a los bienes constitucionales que pueden colisionar con ellos, explica SÁNCHEz GIL, R., El principio, cit. (n. 24), pp. 52 y 53: "La sola idea de una jerarquía inmanente e inmutable entre los principios constitucionales, elimina cualquier posibilidad de realizar la ponderación que exige la identidad de grado de ambos bienes que en ella intervienen".

${ }^{83}$ Alexy, R., Teoría, cit. (n. 8), p. 92.

${ }^{84}$ SAPAG, M., cit. (n. 24), p. 187, expresa que en la regla de ponderación, "de acuerdo con una concepción bastante extendida, se trata de una ponderación entre los principios en juego".

${ }^{85}$ El Diccionario de la Real Academia Española define el verbo ponderar precisamente como "determinar el peso de algo".

${ }^{86}$ En este sentido parece pronunciarse SÁNCHEZ GIL, R., El principio, cit. (n. 24), pp. 48-49, cuando, de modo algo impreciso, afirma que la regla de proporcionalidad supone una ponderación, es decir, "una valoración entre un derecho fundamental o principio constitucional y el fin legislativo que origina su menoscabo, a través del examen de los gravámenes que se imponen recíprocamente". 
producida por la medida o por la conducta en la esfera de un principio o derecho, mayor o más urgente ha de ser también la necesidad de realizar el principio en pugna" 87 .

El objetivo de la ponderación es determinar si los beneficios que reporta la medida son mayores o menores que los perjuicios que genera sobre los intereses constitucionales involucrados en la colisión ${ }^{88}$. En ese entendido, se puede afirmar que la medida sometida a evaluación es constitucional cuando el beneficio que aquella reporta para los derechos fundamentales o bienes constitucionales que se pretende proteger o promover es superior al costo que la misma significa para el derecho fundamental afectado ${ }^{89}$. Si, por

${ }^{87}$ Prieto Sanchís, L., cit. (n. 34), p. 136.

${ }^{88}$ Reiterando lo expuesto en otras cuatro sentencias, el Tribunal constitucional español afirma en la sentencia 186/2000, de 10 de julio de 2000, fundamento jurídico $6^{\circ}$, párrafo quinto, que el principio de proporcionalidad exige evaluar, además de la idoneidad y necesidad de la medida, "si la misma es ponderada o equilibrada, por derivarse de ella más beneficios o ventajas para el interés general que perjuicios sobre otros bienes o valores en conflicto (juicio de proporcionalidad en sentido estricto)". Similar es la posición de RoJAs, I. Y., cit. (n. 16), p. 9, cuando afirma que la regla de ponderación se aplica con el fin de determinar, mediante ponderación, "si el sacrificio de los intereses individuales que comporta la injerencia guarda una relación razonable o proporcional con la importancia del interés estatal que se trata de salvaguardar". Nogueira AlCALÁ, Humberto, La libertad personal y las dos caras de Jano en el ordenamiento jurídico chileno, en Revista de Derecho, 13 (Valdivia, diciembre de 2002), p. 166, por su parte, reitera esta idea cuando afirma que la regla de ponderación consiste en ponderar "si el sacrificio de los intereses individuales que trae consigo la intervención y afectación de la libertad personal guarda una relación proporcionada y razonable con la importancia del interés público que se trata de preservar". En este punto es conveniente advertir que la colisión de intereses no siempre implica que de un lado está un interés general, estatal o público, como señalan la sentencia y los autores recién citados. Por ello parece más precisa la idea de Perello Domenech, I., cit. (n. 27), p. 71, explica que la regla de ponderación exige comprobar "si existe un equilibrio entre las ventajas y perjuicios que se generan por la limitación de un derecho para la protección de otro bien o derecho constitucionalmente protegido".

${ }^{89}$ Aunque con un énfasis distinto, en este mismo sentido se pronuncia BERNAL Pulido, C., Elprincipio, cit. (n. 24), p. 760, cuando explica que el principio de proporcionalidad exige que "las ventajas que se obtienen mediante la intervención legislativa [mediante la medida enjuiciada, se diría en este trabajo] en el derecho fundamental deben compensar los sacrificios que ésta implica para sus titulares y para la sociedad en general". No es exacto, en consecuencia, explicar que la regla de ponderación exige que los "beneficios y ventajas derivados de la restricción del derecho deben ser siempre superiores a los perjuicios sobre otros bienes o intereses en conflicto", como sugiere PERELlo Domenech, I., cit. (n. 27), p. 71, porque los perjuicios no recaen sobre "otros bienes o intereses en conflicto", sino precisamente sobre el derecho restringido. Por tanto, en realidad la cuestión es ligeramente distinta: la regla de ponderación exige que los beneficios y ventajas derivados de la restricción al derecho (que se traducen en favo- 
el contrario, "el sacrificio resulta excesivo, la medida deberá considerarse inadmisible, aunque satisfaga el resto de presupuestos y requisitos derivados del principio de proporcionalidad"90.

Ahora bien, la forma de determinar qué gana y qué pierde cada uno de los derechos fundamentales o bienes constitucionales involucrados en el caso es la argumentación jurídica. Dicho de otro modo, las razones que se aduzcan a favor o en contra de la prevalencia de unos u otros intereses determinarán cuánto ganan y cuánto pierden bajo las circunstancias dadas. En consecuencia, uno de los intereses constitucionales tiene mayor peso que el otro en el caso concreto si existen buenas razones para que ese interés preceda al otro bajo las condiciones del caso concreto ${ }^{91}$.

En síntesis, la regla de ponderación evalúa la constitucionalidad de la medida sometida a control mediante una ponderación que permita determinar qué interés constitucional debe ser preferido y cuál debe ceder, a partir de las condiciones del caso concreto (criterio de la precedencia condicionada) ${ }^{92}$.

Esto muestra que, mientras las reglas de idoneidad y necesidad enjuician directamente la medida sometida a control, la regla de ponderación la enjuicia de modo indirecto. En efecto, los dos primeros evalúan la eficacia y eficiencia de la medida, mientras que el último pondera los derechos fundamentales e intereses constitucionales que colisionan en el caso como consecuencia de la aplicación de la medida sometida a control ${ }^{13}$.

\section{Operaciones necesarias para la aplicación de la regla de ponderación.}

Las operaciones exigidas para la aplicación de la regla de ponderación son cuatro 94 .

recer el disfrute de un derecho fundamental o de un bien jurídico constitucional) sean superiores a los perjuicios sobre el derecho fundamental restringido.

${ }^{90}$ Rojas, I. Y., cit. (n. 16), p. 9.

${ }^{91}$ Alexy, Teoría, cit. (n. 8), p. 93, explica que para determinar cuál de los intereses constitucionales debe ser preferido y cuál debe ceder en el caso de la medida evaluada, es necesario atender a las razones que se ofrezcan a favor de uno y de otro, bajo las específicas condiciones del caso concreto.

${ }^{92} \mathrm{El}$ problema de la regla de ponderación, como advierte SÁnchez GIL, R., El principio, cit. (n. 24), pp. 49-50, es que puede dar lugar a la subjetividad del juzgador. Aunque las tareas que en este momento se revisan pretenden atenuar dicha subjetividad, no se puede negar que la ponderación implica siempre un grado de valoración teñida por las opciones valóricas del juzgador.

${ }^{93}$ En este mismo sentido, Bernal Pulido, C., El principio, cit. (n. 24), pp. 760 y 761, afirma que "Los objetos normativos que se ponderan son, por una parte, el derecho fundamental afectado y, por la otra, el derecho fundamental o el principio constitucional de primer o de segundo grado que fundamenta la [medida]".

${ }^{94}$ Para la formulación de estas tareas se han seguido las ideas vertidas por AlEXY, R., Teoría, cit. (n. 8), especialmente PP. 89 a 97; CLÉRICO, L., cit. (n. 9), pp. 196-197; 
La primera consiste en determinar el peso de los derechos fundamentales y los bienes constitucionales favorecidos con la medida sometida a control en el caso concreto ${ }^{95}$. El peso de estos intereses constitucionales se determina atendiendo a la probabilidad, eficacia, rapidez, alcance y duración con la que se protegerán o promoverán esos mismos intereses, de acuerdo con las condiciones dadas en el caso. Estos serán aquí denominados criterios del peso.

En segundo lugar se debe determinar el peso del derecho fundamental afectado por la medida sometida a control en el caso concreto ${ }^{96}$. Para determinar el peso de este derecho fundamental es necesario atender a los aquí denominados criterios del peso, esto es, la probabilidad, eficacia, rapidez, alcance y duración con que se intervendrá el mismo, de acuerdo con las condiciones dadas en el caso.

La centralidad de los criterios del peso exigen explicar, del modo más conciso posible, en qué consiste cada uno de ellos. El criterio de la probabilidad alude a la certidumbre de los efectos sobre los derechos fundamentales o bienes jurídicos constitucionales involucrados en la colisión, es decir, si se trata de una posibilidad poco probable, de una posibilidad muy probable o de una consecuencia cierta. El criterio de la eficacia se refiere al grado en que se favorecerá el interés constitucional protegido o promovido o en que se perjudicará el derecho fundamental afectado. El criterio de la rapidez dice relación con la prontitud con que se favorecerá o perjudicará el interés constitucional en colisión, es decir, si ocurrirá de inmediato, en breve plazo o en el largo plazo. El criterio del alcance alude al haz de facultades o posibilidades incluidas en los derechos fundamentales o en los bienes constitucionales involucrados en la colisión que resultan favorecidos o perjudicados. Por último, el criterio de la duración atiende a la cantidad de tiempo durante el cual se verá perjudicado o favorecido el interés constitucional de que se trate. Por cierto no siempre será posible aplicar todos estos criterios, pues ello depende de las condiciones del caso concreto.

En tercer lugar, la aplicación de la regla de ponderación consiste en determinar cuál de los intereses constitucionales en colisión presenta un

Bernal Pulido, C., El principio, cit. (n. 24), especialmente pp. 761 a 778; y SánCHEZ GIL, R., El principio, cit. (n. 24), especialmente pp. 48 a 54.

${ }^{95}$ Alexy explica que uno de los pasos de la ponderación consiste en determinar "la importancia de la satisfacción del principio que juega en sentido contrario" a aquél que se está restringiendo. AleXy, R., La fórmula del peso (traducción castellana de Carlos Bernal Pulido), en Alexy, R., y otros, El principio de proporcionalidad en la interpretación jurídica (Santiago de Chile, Librotecnia, enero de 2010), p. 20.

${ }^{96}$ En palabras de Alexy, R., La fórmula, cit. (n. 95), p. 20, otro de los pasos de la ponderación consiste en "definir el grado de la no satisfacción o de afectación de uno de los principios". 
mayor peso, a partir de las condiciones del caso concreto ${ }^{97}$. Para estos efectos es necesario transformar la evaluación del peso de cada uno de esos intereses en razones para la decisión. Esto permitirá determinar si existen razones suficientes para que los derechos fundamentales afectados cedan a favor de los derechos fundamentales e intereses constitucionales favorecidos, o si estos últimos deben ceder a favor de los primeros.

Por último se debe explicitar la relación de precedencia condicionada entre los intereses constitucionales en colisión, bajo las condiciones del caso concreto. En otras palabras, se debe indicar qué interés debe prevalecer y, en consecuencia, cuál debe ceder. Esto se traduce en formular una regla en la que se indiquen las condiciones del caso concreto que conducen a preferir los derechos fundamentales o bienes constitucionales favorecidos por la medida por sobre el derecho fundamental afectado, o que conducen al resultado contrario ${ }^{98}$.

Ahora bien, la aplicación de la regla de ponderación no es lógicamente posible si no se han realizado, previamente, las tareas exigidas por la regla de adecuación. Ello se debe a que si no se identifican la medida y su finalidad, así como la idoneidad teleológica e instrumental de la medida sometida a control, no es posible saber si la medida efectivamente favorece el disfrute de algún derecho fundamental o de algún bien jurídico constitucional. Y sólo si se ha verificado que la medida favorece alguno de estos intereses constitucionales, resulta posible determinar si lo que ellos ganan es más de lo que pierde el derecho fundamental afectado por la aplicación de aquella medida.

Por otra parte, no es metodológicamente conveniente aplicar la regla de ponderación si previamente no se ha evaluado si la medida supera la regla de necesidad. Esto se debe a que, si no supera el juicio de necesidad, significa que puede ser reemplazada por otra medida que permite alcanzar el mismo beneficio para los derechos fundamentales o para los bienes constitucionales favorecidos, con un menor costo (o sin costo) para los derechos fundamentales afectados. Y si puede ser reemplazada por una opción de menor costo o sin costo para los derechos fundamentales, significa que no es indispensable. De este modo, se hace evidente la inconveniencia de evaluar la constitucionalidad de una medida que no es indispensable ${ }^{99}$.

${ }^{97}$ En este mismo sentido, Alexy, R., La fórmula, cit. (n. 95), p. 20, sostiene: "Finalmente, en un tercer paso, debe definirse si la importancia de la satisfacción del principio contrario justifica la restricción o la no satisfacción del otro".

${ }^{98} \mathrm{Al}$ respecto expresa CLÉRICO, L., cit. (n. 9), p. 180: "El resultado de una ponderación entre principios debe poder ser reformulado como una regla: cuando la condición C se cumple, entonces vale la consecuencia jurídica del principio que logró primacía".

${ }^{99}$ Como se puede advertir, mientras la aplicación de la regla de adecuación es condición lógica de la regla de ponderación, la aplicación de la regla de necesidad es condi- 


\section{Aplicación de la regla de ponderación a un caso judicialmente resuelto.}

Ahora debemos estudiar la aplicación de la regla de ponderación a un caso de imposición forzada de tratamiento contra el cáncer a un menor de edad. Ahora bien, aunque no es lógicamente imprescindible evaluar la medida a la luz de la regla de necesidad para aplicar el de proporcionalidad en sentido estricto, el mejor cumplimiento de los objetivos de este trabajo lo recomienda. En consecuencia, a continuación se enjuiciará dicha medida aplicándole sucesivamente las tareas exigidas por las reglas de idoneidad, necesidad y proporcionalidad en sentido estricto, en ese mismo orden.

Según se ha explicado, el principio de proporcionalidad sólo resulta aplicable si la medida perjudica un derecho fundamental. Pues bien, en este caso la medida perjudica el derecho fundamental a la vida ${ }^{100}$, en el sentido del derecho a una vida digna, esto es, una vida que merezca la pena ser vivida ${ }^{101}$. No resulta posible extenderse aquí respecto de los argumentos que permiten entender que este derecho a una vida digna, es decir, a una vida que merezca la pena ser vivida, integra el derecho fundamental a la vida del artículo 19 , número 1, de la Constitución, de modo que su iusfundamentalidad se considera un supuesto del análisis que sigue ${ }^{102}$.

a) Evaluación bajo la regla de idoneidad. Según se recordará, las operaciones comprendidas por la regla de idoneidad son cuatro:

i) Identificación de la medida sometida a control. La medida sometida a control consistió en la pretensión de aplicar forzadamente un tratamiento médico a un menor de 11 años que padecía leucemia linfoplástica aguda, y al cual se oponían tanto el menor como su madre.

ii) Identificación de la finalidad de la medida sometida a control. De

ción técnica (vinculada a maximizar el disfrute de los derechos fundamentales) de este último.

${ }^{100}$ Artículo $19 \mathrm{~N}^{\circ} 1$ C.PolCh.

${ }^{101}$ Este derecho a la vida digna es definida por Figueroa YáñEz, Gonzalo, El "derecho a la vida" y el "derecho a hacer la vida" en colisión: Algunas consideraciones frente a una sentencia judicial, en Revista Chilena de Derecho Privado [online], 12 (2009), p. 210 [citado en línea el 10 de noviembre de 2010], como "el derecho a elegir la vida que cada cual desea llevar, a escoger los valores que le darán sentido, al esfuerzo por desarrollarse en la búsqueda de tales valores, a vivir la vida escogida e, incluso, al derecho a morir por esos valores", y se funda "en el concepto de dignidad aplicado a la vida biológica”..

${ }^{102}$ En este caso se ha preferido hablar de un derecho que "integra" el derecho fundamental a la vida, para evitar explicaciones adicionales. Sin embargo, más preciso es hablar de derechos conferidos por normas adscritas a una norma directamente estatuida en la Constitución. En este sentido, En palabras de Alexy,Teoría, cit. (n. 8), pp. 66 a 73 , son derechos fundamentales no sólo los conferidos por normas directamente estatuidas en la Constitución, sino también aquellos concedidos por normas que pueden ser adscritas a las primeras. 
acuerdo con lo expresado en el oficio remitido por el Hospital Base de Valdivia al juzgado de familia de la misma ciudad, la finalidad de la medida era proteger la vida del menor, en el sentido de su subsistencia biológica ${ }^{103}$.

iii) Evaluación de idoneidad teleológica de la medida. La medida es teleológicamente idónea, pues persigue una finalidad legítima. En efecto, con ella se pretende la subsistencia biológica del menor, lo que implica asegurar el derecho fundamental a la vida estatuido en el artículo 19, número 1, inciso primero, de la Constitución.

$i v)$ Evaluación de idoneidad técnica de la medida. La medida es técnicamente idónea, pues constituye un medio adecuado para conseguir una finalidad legítima. En efecto, someter al menor al tratamiento médico prescrito por el Hospital le ofrece un $40 \%$ de posibilidades de sobrevida ${ }^{104}$.

Que la medida supere satisfactoriamente la evaluación a que le somete la regla de idoneidad no significa que es constitucional. Sólo significa que ha superado una primera etapa y, en consecuencia, corresponde la evaluación bajo la regla de necesidad.

b) Evaluación bajo la regla de necesidad. Lasoperaciones exigidas por la regla de necesidad también son cuatro, pero el resultado positivo de cualquera de ellas hace inncesario proseguir con los otros. Es nuestro caso, pues la "identificación de medios alternativos" conduce a este reusultado: la alternativa médica a la que se somete al menor, en lugar de la quimioterapia, es la denominada "medicina alternativa", según declara la propia madre. Sin embargo, no se puede considerar un medio alternativo a la medicina tradicional, pues no existe certidumbre respecto de la eficacia de esta última ${ }^{105}$.

Pues bien, y según se explicó al exponer las tareas incluidas en la regla de necesidad, si no existe una medida alternativa al menos igualmente eficaz que la sometida a control, entonces esta última es una medida necesaria. En consecuencia, en este punto cesa la evaluación desde el punto de vista de la regla mencionado y se debe proceder a evaluarla desde la regla de pondera-

${ }^{103}$ Véase sentencia del Juzgado de familia de Valdivia de 7 de abril de 2009, recaída en la causa rol $\mathrm{N}^{\circ} 178$, sobre medida de protección, considerando primero.

${ }^{104}$ Así lo expresó en estrados la médico tratante del menor, de especialidad oncóloga infantil. Véase sentencia del Juzgado de familia de Valdivia de 7 de abril de 2009, recaída en la causa rol $\mathrm{N}^{\circ} 178$, sobre medida de protección, considerando cuarto.

${ }^{105} \mathrm{La}$ Corte de Apelaciones de Valdivia se pronuncia expresamente sobre la medicina alternativa como medio que pueda reemplazar a la medicina tradicional. Al respecto señala que no es posible saber cuáles son las posibilidades de la misma, pues "son evaluaciones que ni siquiera quienes tienen la experticia cientifica pueden hacer con una razonable dosis de seguridad". Y, con acierto, concluye: "No es, por tanto, un a evaluación de esa clase la que permitirá resolver la controversia planteada a esta Corte". Véase sentencia de la Corte de Apelaciones de Valdivia de 14 de mayo de 2009, recaída en la causa rol $\mathrm{N}^{\circ}$ 103-2009, sobre medida de protección. 
ción. Esto significa que no se requiere realizar los otros tres pasos incluidos en la regla de necesidad.

c) Evaluación bajo la regla de ponderación. Las tareas que se deben cumplir en el ámbito de la regla de ponderación son: $i$ ) determinar el peso de los derechos fundamentales o bienes constitucionales favorecidos con la medida evaluada en el caso concreto; ii) determinar el peso del derecho fundamental afectado por la medida sometida a control en el caso concreto; iii) determinar cuál de los intereses constitucionales en colisión presenta un mayor peso en el caso concreto; y iv) explicitar la relación de precedencia condicionada entre los intereses constitucionales en colisión a partir de las circunstancias del caso.

i) Peso de los intereses constitucionales favorecidos. El interés constitucional favorecido en el caso es el derecho a la vida, en el sentido de derecho a la subsistencia biológica. Utilizando los criterios del peso, resulta posible presentar la siguiente evaluación del peso de este interés:

El favorecimiento del derecho fundamental a la subsistencia biológica tiene una probabilidad del $40 \%$, de modo que el tratamiento "no garantiza ", en modo alguno, la curación de la enfermedad que lo afecta” ${ }^{106}$, más aún si se considera que la enfermedad reapareció, pero agravada con cáncer testicular luego de un tratamiento similar al que se desea aplicar ahora ${ }^{107}$.

El tiempo durante el cual se favorecerá el derecho fundamental a la subsistencia biológica es indeterminado, pues el menor tuvo una nueva recaída tras dieciocho meses de concluido un tratamiento similar ${ }^{108}$.

El alcance del favorecimiento del derecho fundamental a la subsistencia biológica es incompleto, porque el nuevo tratamiento de quimioterapia incluye la extirpación testicular, como condición de su probabilidad de éxito ${ }^{109}$, de modo que no resultan favorecidos todos los ámbitos o posibilidades de la existencia biológica.

ii) Peso de los derechos fundamentales perjudicados. El derecho fundamental afectado con la medida es el derecho a la vida, en el sentido de derecho a una vida digna, que merezca la pena ser vivida. Utilizando los

${ }^{106}$ Sentencia de la Corte de Apelaciones de Valdivia de 14 de mayo de 2009, recaída en la causa rol $N^{\circ} 103-2009$, sobre medida de protección, considerando séptimo.

${ }^{107}$ Sentencia de la Corte de Apelaciones de Valdivia de 14 de mayo de 2009, recaída en la causa rol $\mathrm{N}^{\circ} 103-2009$, sobre medida de protección, considerando décimo sexto.

${ }^{108}$ Sentencia de la Corte de Apelaciones de Valdivia de 14 de mayo de 2009, recaída en la causa rol $\mathrm{N}^{\circ} 103-2009$, sobre medida de protección, considerandos tercero y quinto.

${ }^{109}$ Sentencia de la Corte de Apelaciones de Valdivia de 14 de mayo de 2009, recaída en la causa rol $N^{\circ} 103-2009$, sobre medida de protección, considerando séptimo. 
criterios del peso, resulta posible presentar la siguiente evaluación del peso de este interés:

La probabilidad del perjuicio del derecho fundamental a una vida digna, que merezca la pena vivirla, es seguro, pues "resulta asimismo cierto que la práctica de los citados tratamiento y operación le acarrearán al niño los mismos o mayores trastornos físicos y síquicos que en la ocasión anterior" ${ }^{110}$.

La oportunidad en que se afectará el derecho fundamental a una vida digna, que merezca la pena vivirla, es inmediata, tan pronto como comience el tratamiento de quimioterapia.

La duración del perjuicio al derecho fundamental a una vida digna, que merezca la pena vivirla, puede ser de años, si se considera que el tratamiento anterior se le había suministrado entre el 2005 y el 2007 al mismo menor ${ }^{111}$. Si a esto se le añaden las posibilidades de éxito del tratamiento, la lesión a este derecho podría incluso extenderse por el resto de la vida de su titular.

iii) Determinar cuál de los intereses constitucionales en colisión presenta mayor peso. El derecho fundamental a la subsistencia biológica parece tener un peso relativamente pequeño si se considera que:

El tratamiento no asegura curar la enfermedad, pues presenta una probabilidad del $40 \%$ y similar tratamiento anterior no evitó el resurgimiento de la enfermedad, ahora agravada con cáncer testicular.

Su duración es indeterminada si se considera que el tratamiento anterior sólo fue efectivo por 18 meses.

No resultan favorecidos todos los aspectos de la vida biológica debido a que el tratamiento incluye extirpación testicular.

Por su parte, el derecho fundamental a una vida digna, que merezca la pena vivirla, tiene un peso importante si se considera: que la probabilidad de lesionarlo es segura, debido a que el tratamiento significará al menor severos padecimientos físicos y síquicos; lo que ocurrirá tan pronto como aquel se inicie; y que puede prolongarse por años e incluso por el resto de la vida del menor.

iv) Formular relación de precedencia condicionada. La imposición de un tratamiento de quimioterapia contra el cáncer está prohibida si presenta escasas probabilidades de éxito según las proyecciones y la experiencia de similar tratamiento anterior fallido; el anterior tratamiento sólo fue eficaz por 18 meses; si implica el cercenamiento de un miembro importante, y todo a cambio de provocar severos padecimientos físicos y síquicos al paciente,

${ }^{110}$ Sentencia de la Corte de Apelaciones de Valdivia de 14 de mayo de 2009, recaída en la causa rol $N^{\circ} 103-2009$, sobre medida de protección, considerando séptimo.

${ }^{111}$ Sentencia de la Corte de Apelaciones de Valdivia de 14 de mayo de 2009, recaída en la causa rol $\mathrm{N}^{\circ} 103-2009$, sobre medida de protección, considerando tercero. 
tan pronto como se inicia su aplicación y lo que incluso puede prolongarse por el resto de la vida del mismo.

La consecuencia de esta relación de precedencia es que, de acuerdo con las condiciones del caso concreto, el derecho fundamental a la subsistencia biológica debe ceder frente al derecho a una vida digna, que merezca la pena ser vivida.

\section{Conclusiones}

a) Según se explicó al inicio de este trabajo, su objetivo ha sido exponer cómo se aplica el examen de proporcionalidad en el Derecho constitucional. Dicho con mayor precisión, se ha pretendido explicar cómo debe operar este principio al momento de evaluar la constitucionalidad de una medida lesiva de derechos fundamentales con la que, real o aparentemente, se pretende favorecer un derecho fundamental o un bien constitucional.

b) Lo expuesto ha mostrado que el examen de proporcionalidad permite alcanzar decisiones judiciales correctas, esto es, decisiones judiciales que permiten el mayor disfrute posible de los derechos fundamentales, dentro de las posibilidades conferidas por las justificaciones en que se funda la medida que pretende limitarlos.

Según se ha visto, ello se debe a que la aplicación del examen de proporcionalidad permite optimizar el disfrute de los derechos fundamentales, mediante la pronta exclusión de aquellas medidas que no conducen a satisfacer intereses constitucionales (regla de idoneidad) o que pueden ser reemplazadas por otras medidas menos gravosas para los derechos fundamentales (regla de necesidad) o que son desproporcionadas (regla de ponderación).

Inversamente, el examen de proporcionalidad permite optimizar el disfrute de los derechos fundamentales porque admite su restricción sólo cuando la medida efectivamente promueve un derecho fundamental o un bien constitucional (regla de adecuación), sin que existan medidas alternativas menos lesivas para los derechos fundamentales (regla de necesidad) y lo que se gana desde el punto de vista de los intereses constitucionales promovidos es más que lo que se pierde desde el punto de vista del derecho fundamental restringido (regla de ponderación).

c) En este trabajo se ha mostrado, además, que el examen de proporcionalidad ofrece un procedimiento claro y sencillo en orden a generar decisiones judiciales correctas.

En efecto, el examen de proporcionalidad constituye un instrumento de control de constitucionalidad de medidas restrictivas de derechos fundamentales que se aplica con claridad. Esto se debe a que cada una de las tres reglas que lo constituyen está integrada por un conjunto de tareas bien 
identificadas. Cada una de esas tareas, a su turno, conduce a consecuencias igualmente precisas, las que se traducen en declarar la inconstitucionalidad del la medida enjuiciada o a una nueva tarea de evaluación y eventual declaración de admisibilidad constitucional.

Por otra parte, y relacionado con lo anterior, el examen de proporcionalidad ofrece un relativamente simple procedimiento de evaluación de constitucionalidad de las medidas restrictivas de derechos fundamentales. En efecto, se trata de un instrumento que se aplica mediante la lógica de gradas. Esto significa que cada una de sus tres reglas y de las tareas exigidas por cada una de ellas deben ser aplicadas sucesivamente. Esas reglas y tareas, a su turno, se encuentran lógicamente concatenadas. En consecuencia, basta con conocer la estructura del principio y de sus reglas para comprender su modo de aplicación.

d) Se debe advertir que las ventajas del examen de proporcionalidad relativas a su capacidad para conducir a decisiones judiciales correctas de modo claro y sencillo resultan beneficiosas para dos categorías de sujetos. De un lado, para quien debe evaluar la constitucionalidad de una medida restrictiva de derechos fundamentales. Ello se debe a que ofrece un procedimiento estandarizado de razonamiento, el que esencialmente consiste en seguir las tareas establecidas para cada una de las reglas. De otro lado, es beneficioso para los destinatarios de esas decisiones y, en general, para cualquier observador de las mismas. A todos ellos les permite reconstruir el razonamiento seguido y advertir tanto los aciertos como los posibles fallos del proceso de argumentación de la decisión. En este sentido, se trata de un procedimiento cuyos resultados pueden ser intersubjetivamente controlados.

e) Lo dicho no significa que la aplicación del examen de proporcionalidad está exenta de dificultades. Tampoco significa que el examen de proporcionalidad resulta siempre aplicable para evaluar medidas restrictivas de derechos fundamentales ${ }^{12}$. Sin embargo, estas limitaciones no deben argumentar a favor de un abandono del examen de proporcionalidad. Precisamente al contrario, deben constituir nuevos alicientes para una mejor comprensión y aplicación de este instrumento que, en palabras de Alexy, constituye el "más importante principio del derecho constitucional material" 113 . Y ello porque cada nuevo aporte en este sentido es un nuevo paso a favor de decisiones judiciales correctas, en el sentido explicado en este trabajo.

Por lo mismo, problemas tales cómo superar las contradicciones entre

${ }^{112}$ Así, por ejemplo, no resulta aplicable a un caso en el que no hay claridad sobre los hechos, sobre el significado de las disposiciones jurídicas involucradas o sobre el contenido de los derechos fundamentales. Y ello porque no se trata de un mecanismo de valoración de la prueba, de interpretación jurídica ni de interpretación iusfundamental.

${ }^{113}$ Alexy, R., La fórmula, cit. (n. 95), p. 19. 
finalidades declaradas y finalidades reales en el ámbito de la regla de idoneidad, a quién corresponde demostrar la existencia (o inexistencia) de medios alternativos menos lesivos para los derechos fundamentales en el ámbito de la regla de necesidad, o cómo limitar las valoraciones en el ámbito de la regla de ponderación, entre muchos otros, deben ser enfrentados. Estudiar estos y otros problemas permitirá generar una mejor justicia y un mayor disfrute de los derechos fundamentales, los que constituyen el pilar central del ordenamiento jurídico y del Estado de Derecho, de acuerdo con el modo en que actualmente hemos consensuado entenderlos.

\section{BiBLIOGRAFÍA}

AleXY, Robert, La fórmula del peso, en AleXY, Robert, y otros, Elprincipio deproporcionalidad en la interpretación jurídica (traducción castellana de Carlos Bernal Pulido, Santiago de Chile, Librotecnia, 2010).

Alexy, Robert, Teoría de los derechos fundamentales (traducción castellana de Ernesto Garzón Valdés, Madrid, Centro de Estudios Políticos y Constitucionales, 2001).

Barranco Avilés, María del Carmen, Derechos y decisiones interpretativas (Madrid - Barcelona, Marcial Pons, 2004).

Bernal Pulido, Carlos, El juicio de igualdad en la jurisprudencia de la Corte Constitucional Colombiana, en VEGA GómEz, Juan - CoRzo Sosa, Edgar. Instrumentos de tutela y justicia constitucional, Memoria del VII Congreso Iberoamericano de Derecho constitucional (Ciudad de México, Instituto de Investigaciones Jurídicas, 2002) [disponible en: http://www.bibliojuridica.org/libros/libro.htm?l=344. Consulta: 4 noviembre 2010].

Bernal Pulido, Carlos, El principio de proporcionalidad y los derechos fundamentales ( $2^{\text {a }}$ edición, Madrid, Centro de Estudios Políticos y Constitucionales, 2005).

CARpIzo, Jorge, El Tribunal Constitucional y el control de la reforma constitucional, en Boletin Mexicano de Derecho Comparado, 125 (mayo-agosto de 2009) [disponible en www.ejournal.unam.mx/bmd/bolmex125/BMD000012506.pdf. Consulta: 3 noviembre 2010].

ClérICo, Laura, El examen de proporcionalidad en el Derecho constitucional (Buenos Aires, Eudeba, 2009).

FERrada Bórquez, Juan Carlos, en Abriendo camino en la tutela de derechos fundamentales en materia laboral: buenas intenciones, malos instrumentos (Juzgado de Letras del Trabajo de Copiapó), en Revista Derecho, 21 (Valdivia, 2008) [disponible en: http:// www.scielo.cl/scielo.php?script=sci_arttext\&pid=S0718-09502008000200010\&lng=es\&nrm=iso].

FERRADA BórQueZ, Juan Carlos, Los derechos fundamentales y el control constitucional, en Revista de Derecho, 17 (Valdivia, 2004) [disponible en: http://www.scielo.cl/scielo. php?script=sci_arttext\&pid=S0718-09502004000200005\&lng=es\&nrm=iso].

Figueroa YÁÑEz, Gonzalo, El "derecho a la vida” y el "derecho a hacer la vida” en colisión: Algunas consideraciones frente a una sentencia judicial, en Revista Chilena de Derecho Privado, 12 (2009), [disponible en: http://www.scielo.cl/scielo.php?script=sci_ arttext\&pid=S0718-80722009000100006\&lng=es\&nrm=iso]. 
González BeIlfuss, Markus, Últimas tendencias en la interpretación del principio de proporcionalidad por parte del Tribunal Constitucional español, en CARRASCO Durán, Manuel - PÉrez Royo, Francisco Javier - Urías Martínez, Joaquín Terol Becerra, Manuel José (coordinadores), Derecho constitucional para el siglo XXI: actas del VIII Congreso Iberoamericano de Derecho Constitucional (España, Aranzadi, 2006) II [disponible en: http://congreso.us.es/cidc/Ponencias/justicia/ MarkusGonzalez.pdf].

Martínez Zorrilla, David, Dilemas morales y Derecho, en Discusiones, 8 (2008) [disponible en http://www.bibliotecadigital.uns.edu.ar/scielo.php?script=sci_ arttext\&pid=S1515-73262008000100003\&lng=en\&nrm=iso. Consulta: 02/09/2010].

Nogueira Alcalá, Humberto, Dogmática constitucional (Talca, Editorial Universidad de Talca, 1997).

Nogueira Alcalá, Humberto, La libertad personal y las dos caras de Jano en el ordenamiento jurídico chileno, en Revista de Derecho, 13 (Valdivia, 2002) [disponible en: http://mingaonline.uach.cl/scielo.php?script=sci_arttext\&pid=S071809502002000100011\&lng=es\&nrm=iso].

Peces-Barba, Gregorio, Derechos fundamentales ( $3^{\text {a }}$ edición, Madrid, Latina Universitaria, 1980).

Perello Domenech, Isabel, El principio de proporcionalidad y la jurisprudencia constitucional, en Jueces para la democracia, 28 (1997).

Prieto Sanchís, Luis, El juicio de ponderación constitucional, en Alexy, Robert y otros, El principio de proporcionalidad en la interpretación constitucional (Santiago de Chile, Librotecnia, 2010).

Rojas, Ivonne Yenissey, Elprincipio deproporcionalidad de laspenas (s.l., s.d.) [disponible en: http://derecho.maz.uasnet.mx/Revista_juridica_agora/documentos_comprimidos_publicaciones/trabajo\%20ivon.pdf].

SÁnCHEZ Gil, Rubén, El principio de proporcionalidad (Ciudad de México, Instituto de Investigaciones Jurídicas, 2007) [disponible en http://www.bibliojuridica.org/ libros/libro.htm?l=2422].

SÁNCHEZ GIL, Rubén, Elprincipio de proporcionalidad en la jurisprudencia mexicana, en AlEXY, Robert y otros, El principio de proporcionalidad en la interpretación jurídica (Santiago de Chile, Librotecnia, 2010).

SAPAG, Mariano A., El principio de proporcionalidady de razonabilidad como limite constitucional alpoder del Estado: Un estudio comparado, en Dikaion, 22 (diciembre 2008) 17 [disponible en: http://redalyc.uaemex.mx/redalyc/pdf/720/72011607008.pdf. Consulta: 2 septiembre 2010].

SARmiento, Daniel, El principio de proporcionalidad y la defensa de la autonomia local, en Revista de Administración Pública, 162 (septiembre-diciembre 2003) [disponible en: http://www.cepc.es/revistas/revistas.aspx?IDR=1\&IDN=160\&IDA=24517. Consulta: 2 septiembre 2010].

Silva Bascuñán, Alejandro, Tratado de Derecho constitucional (2a edición, Santiago de Chile, Editorial Jurídica de Chile, 1997), I.

VIDAl Fueyo, Camino, El principio de proporcionalidad como parámetro de constitucionalidad de la actividad del juez, en Anuario de Derecho constitucional Latinoamericano, 2 (2009) 2 [disponible en: www.juridicas.unam.mx/publica/librev/rev/dconstla/.../ pr2.pdf. Consulta: 2 septiembre 2010]. 
Zúñ Iga AÑasco, Yanira, El principio de proporcionalidad como herramienta de racionalidad. Un análisis crítico de su aplicación en la jurisprudencia del Tribunal Constitucional chileno, en Ius et Praxis, 16 (Talca, 2010) 2. 